Illinois State University

ISU ReD: Research and eData

Theses and Dissertations

5-30-2019

\title{
Influence Of Authority And Message Framing On Compliance With Mental Health Treatment Recommendations
}

Morgan A. Ess

Illinois State University, morganessstudent@gmail.com

Follow this and additional works at: https://ir.library.illinoisstate.edu/etd

Part of the Psychology Commons

\section{Recommended Citation}

Ess, Morgan A., "Influence Of Authority And Message Framing On Compliance With Mental Health Treatment Recommendations" (2019). Theses and Dissertations. 1141.

https://ir.library.illinoisstate.edu/etd/1141

This Thesis is brought to you for free and open access by ISU ReD: Research and eData. It has been accepted for inclusion in Theses and Dissertations by an authorized administrator of ISU ReD: Research and eData. For more information, please contact ISUReD@ilstu.edu. 


\section{INFLUENCE OF AUTHORITY AND MESSAGE FRAMING \\ ON COMPLIANCE WITH MENTAL HEALTH \\ TREATMENT RECOMMENDATIONS}

\section{MORGAN A. ESS}

\section{Pages}

The purpose of this study was to investigate the influence of source authority and message framing on compliance with mental health treatment recommendations. The current study used measures of attitudes and intentions to seek psychological help as well as the likelihood that an individual will request initial counseling information as proxies for observing help-seeking behavior. A pretest and posttest experimental design was implemented. Participants were 273 students at Illinois State University. At pretest, participants completed a demographic questionnaire, the Kessler K6+, the Mental Help Seeking Attitudes Scale (MHSAS), the Mental Help Seeking Intentions Scale (MHSIS), and indicated engagement in past psychological help seeking. At posttest, participants were exposed to a hypothetical mental health treatment recommendation, and recompleted the Kessler K6+, MHSAS, MHSIS, and had the opportunity to request counseling information. No significant main effects were found for source authority on attitudes towards psychological help, intentions to engage in psychological help seeking, or decisions to request counseling information. No significant interaction effects for source authority and message framing were found on intentions to seek psychological help or decisions to request counseling information. Future research could investigate ways to increase mental health treatment utilization by measuring actual help seeking behavior.

KEYWORDS: Authority, Compliance, Mental Health Treatment Recommendations, Message Framing, Persuasion 


\section{INFLUENCE OF AUTHORITY AND MESSAGE FRAMING \\ ON COMPLIANCE WITH MENTAL HEALTH \\ TREATMENT RECOMMENDATIONS}

MORGAN A. ESS

A Thesis Submitted in Partial

Fulfillment of the Requirements

for the Degree of

MASTER OF SCIENCE

Department of Psychology

ILLINOIS STATE UNIVERISTY 
(C) 2019 Morgan A. Ess 


\section{INFLUENCE OF AUTHORITY AND MESSAGE FRAMING \\ ON COMPLIANCE WITH MENTAL HEALTH \\ TREATMENT RECOMMENDATIONS}

MORGAN A. ESS

COMMITTEE MEMBERS:

Daniel G. Lannin, Chair

Suejung Han 


\section{ACKNOWLEDGMENTS}

The completion of this project would not be possible without the support from several individuals. I would like to extend a thank you to my committee member, Dr. Suejung Han. Your valuable feedback and contributions to this project strengthened my research. I would like to give a special thank you to my committee chair, Dr. Daniel Lannin for his guidance, encouragement, and patience throughout the course of this project. Your expertise helped me develop into a more competent researcher and challenged me to learn new skills. I am grateful for both of your commitments to helping your students learn and grow.

M.A.E. 


\section{CONTENTS}

Page

ACKNOWLEDGMENTS

$\begin{array}{ll}\text { CONTENTS } & \text { ii }\end{array}$

TABLES

FIGURES

CHAPTER I: INTRODUCTION 1

CHAPTER II: LITERATURE REVIEW

$\begin{array}{ll}\text { Compliance } & 8\end{array}$

Authority and Compliance $\quad 9$

Authority and Compliance with Health Behavior Recommendations 11

Authority and Compliance with Mental Health Treatment Recommendations 15

Message Framing and Compliance $\quad 16$

Authority, Message Framing, and Compliance $\quad 20$

The Current Study $\quad 21$

$\begin{array}{ll}\text { Purpose } & 21\end{array}$

$\begin{array}{ll}\text { Hypotheses } & 23\end{array}$

Source Effects on Attitudes, Intentions, and Help-seeking Decisions 23

Interaction of Source and Message Framing 23

CHAPTER III: RESEARCH METHODOLOGY 25

$\begin{array}{ll}\text { Participants } & 25\end{array}$

$\begin{array}{ll}\text { Measures } & 25\end{array}$ 
Demographics Questionnaire

$\begin{array}{ll}\text { Psychological Distress } & 25\end{array}$

Past Psychological Help Seeking $\quad 26$

Help Seeking Attitudes 26

$\begin{array}{ll}\text { Help Seeking Intentions } & 27\end{array}$

Decision to Seek Counseling Information 28

$\begin{array}{ll}\text { Study Design } & 28\end{array}$

$\begin{array}{ll}\text { Procedure } & 29\end{array}$

$\begin{array}{ll}\text { High Authority } & 30\end{array}$

$\begin{array}{ll}\text { Low Authority } & 31\end{array}$

Positively Framed Message $\quad 32$

Negatively Framed Message $\quad 32$

CHAPTER IV: RESULTS 34

$\begin{array}{ll}\text { Descriptive Analyses } & 34\end{array}$

$\begin{array}{ll}\text { Manipulation Checks } & 34\end{array}$

$\begin{array}{ll}\text { Main Analyses } & 35\end{array}$

$\begin{array}{ll}\text { CHAPTER V: DISCUSSION } & 41\end{array}$

$\begin{array}{ll}\text { Limitations } & 45\end{array}$

$\begin{array}{lr}\text { Future Directions } & 49\end{array}$

$\begin{array}{ll}\text { Conclusion } & 51\end{array}$

$\begin{array}{ll}\text { REFERENCES } & 53\end{array}$

$\begin{array}{ll}\text { APPENDIX A: INFORMED CONSENT } & 64\end{array}$ 


\section{TABLES}

Table

Page

1. Correlations, Means, and Standard Deviations for Study Variables 38

2. Analysis of Covariance Summary on Attitudes Towards Seeking Psychological Help 39

3. Analysis of Covariance Summary on Intentions to Seek Psychological Help 39

4. Hierarchical Logistic Regression Analysis for Variables Predicting Decisions to Seek Counseling Information 


\section{FIGURES}

Figure $\quad$ Page

1. Four Experimental Conditions in Which Participants were Assigned 


\section{CHAPTER I: INTRODUCTION}

More than a quarter of the United States population has likely experienced a mental health concern in the last 12 months (Kessler, Chiu, \& Demler, 2005), but the majority of these individuals receive no mental health treatment in a given year (Wang et al., 2005). This is unfortunate because treating mental health concerns has been shown to decrease health care costs (Simon, Vonkorff, \& Barlow, 1995), reduce hospital readmission rates (Berge et al., 2017), and improve patients' quality of life (Spitzer et al., 1995). For those receiving treatment for a mental health concern, most are treated in general medical settings (Kroenke, Spitzer, Williams, Monohan, \& Lowe, 2007; Regier, Goldber, \& Taube, 1978; Wang et al., 2005), but this care typically does not meet minimally adequate standards (Wang et al., 2005). Thus, it may be beneficial for primary care physicians to consider the utility of referring patients to mental health service providers. Primary care physicians' referrals for mental health treatment may be powerful for two reasons. First, primary care physicians may function as gatekeepers for mental health services in that their referrals are often necess ary for insurance-reimbursement for mental health treatment. That is, without a referral from their primary care physician many patients may be unlikely to seek adequate treatment for their mental health concern. Second, patients perceive doctors as authority figures due to their expertise (Wrench \& Butterfield, 2009; Goodyear-Smith \& Buetow 2001) and high social status (Goodyear-Smith \& Buetow 2001).

When individuals who are perceived as authority figures provide behavior recommendations, they become authoritative message sources. These authoritative sources have been shown to increase compliance with physical health behavior recommendations (Arora et al., 2006; Hu \& Sundar, 2010; Jones et al., 2003; Kareklas, Muehling, \& Weber, 2015; Meulenaer, Pelsmacker, \& Dens, 2017; Olynick, Iliopulos, \& Li, 2017). Authoritative sources are successful 
at increasing compliance with behavioral requests because people often adhere to requests made by experts or people in positions of power (Cialdini \& Goldstein, 2002). Authoritative sources appear to be successful at increasing health-related behaviors because they have been shown to influence attitudes towards engagement in health-related behaviors (Arora et al., 2006; Case et al., 2018; Kareklas et al., 2015) as well as intentions to engage in health- related behaviors (Arora et al., 2006; Jones et al., 2003; Kareklas et al., 2015). Despite a large body of evidence suggesting that authoritative sources are effective at increasing the likelihood that an individual will engage in a health-related behavior, the literature is not unanimous. Some evidence suggests that authoritative sources do not always increase attitudes towards engaging in a health-related behavior (Jones et al., 2003; Jones et al., 2004) or intentions to engage in a health-related behavior (Falomir- Pichastor et al., 2002; Jones et al., 2004). Despite the mix in the literature, authoritative sources have more often increased attitudes towards, intentions to engage in, and actual health behaviors when compared to non-authoritative sources. Since the majority of individuals with a mental health concern receive no mental health treatment, and authoritative sources can increase compliance with some physical health behavior recommendations, the influence of medical doctors' mental health treatment referrals on the utilization of mental health services is a valuable area to investigate.

Additionally, message framing may also affect compliance with health recommendations. Message framing refers to how one manipulates the emphasis of a message to highlight either the benefits of performing a behavior or the risks of not performing a behavior. Message framing manipulations can influence compliance with a variety of behaviors related to physical health such as increasing physical activity and decreasing smoking (Gallagher \& Updegraff, 2011). Additionally, gain framed messages, which emphasize the benefits of performing a behavior, 
have been shown to be more successful than loss-framed messages, which emphasize the risks of not performing a behavior, at persuading individuals to seek mental health treatment (Mavandadi, Wright, Klaus, \& Oslin, 2017).

It is unknown how the combined influence of perceived source authority and message framing will influence recommendations to seek mental health treatment. Though there is some analogous research in the physical health literature, findings are inconclusive or mixed (Arora, Stoner \& Arora, 2006; Jones, Sinclair, \& Courneya, 2003; Jones, Sinclair, Rhodes, \& Courneya, 2004). For example, Jones and colleagues (2003) found that gain framed messages delivered by an authoritative source led to a significant increase in physical exercise. However, their replication study (Jones et al., 2004) failed to support their own initial findings. Arora and colleagues (2006) also demonstrated a source by message framing interaction effect on intention to engage in physical exercises but in the opposite condition for framing. Specifically, Arora and colleagues (2006) demonstrated that an authoritative source delivering a message in a negative frame led to the most positive intentions to engage in physical exercise. Since studies have shown mixed results regarding the combined effects of message framing and authoritative sources on persuasion, it may be important to examine how perceived authority and message framing influences recommendations to seek mental health treatment.

The purpose of the present study was to investigate practical implications for how mental health concerns are addressed via theoretical guidelines from the broader social influence literature. Specifically, the present study tests the influence of perceived source authority and message framing on compliance with mental health treatment referrals. It is clear that many individuals are negatively impacted by mental health concerns and may benefit from referrals to appropriate mental health treatment; however, these referrals may sometimes either not occur, or 
may not be complied with. The current study explored how perceived source authority and message framing interact to predict compliance with mental health treatment referrals. The current study used attitudes towards and intentions to seek mental health treatment as a proxy for compliance with mental health treatment recommendations. The current study also examined the influence of source authority and message framing on whether a participant requested initial information about Illinois State University's counseling services. 


\section{CHAPTER II: LITERATURE REVIEW}

Mental health concerns are prevalent among the general population in the United States, but despite this prevalence, treatment is often delayed or never sought. A nationally representative study conducted in the United States from 2001-2003 found that $26.2 \%$ of their sample had experienced a mental health concern within the last 12 months (Kessler et al., 2005). Additionally, in the 12 months prior to the survey, only $41.1 \%$ of these individuals received some form of mental health treatment (Wang et al., 2005). Among the individuals that did seek treatment, $22.8 \%$ percent were being treated in the general medical sector, exceeding the percentages of individuals seeking help from a psychiatrist $(12.3 \%)$ or mental health specialist (16\%) (Wang et al., 2005). However, most patients in the general medical sector with a mental health concern are not receiving minimally adequate mental health treatment, defined as either 8 or more sessions of psychotherapy or at least 2 months of medication paired with 4 visits to a physician for medication monitoring and evaluation (Wang, Demler, \& Kessler, 2002: Wang et al., 2005). In one study, $41 \%$ of primary care patients with a diagnosed mental illness did not receive counseling, medication, or psychotherapy (Kroenke et al., 2007), and only 12.7\% of individuals receiving mental health treatment from a general medical provider received adequate care (Wang et al., 2005).

Since mental health concerns affect more than a quarter of the United States population in a given year, it is not surprising that some efforts have already been made to encourage mental health treatment seeking. Because help-seekers experience stigma (i.e., negative perceptions of those having a mental health concern or requiring psychological help; Vogel, Wade, \& Haake, 2006), and this stigma has been shown to prevent individuals from seeking professional mental health treatment (Clement et al., 2014; Lannin et al., 2016), initiatives to reduce stigma have 
been studied and promoted for over 20 years (Corrigan, 1999; Thornicroft et al, 2018). These efforts include social activism, interpersonal contact with individuals who have a mental health concern, and educational approaches such as movies, lectures, and public service announcements (Corrigan et al., 2012). Some stigma-reduction initiatives have been able to produce more favorable attitudes towards seeking professional mental health treatment among individuals struggling with a mental health concern (Esters et al., 1998; Saporito, 2009). However, many of these programs may not be easily implemented or scalable because they usually require inperson attendance, as well as professional presenters to lead the programs. Additionally, and most poignantly, stigma related to mental health concerns may prevent stigmatized individuals from completing stigma-reduction interventions because those interventions make salient their stigma.

The current study examined an alternative approach towards increasing mental health treatment utilization. That is, instead of examining how to reduce barriers to treatment—such as perceptions of stigma - the present study examined how to directly increase compliance. This may be particularly useful, given that this approach may be able to effectively utilize an important authority in patients' lives, their primary care physicians. Indeed, primary care settings have even been coined the, "Defacto mental health service system" (Regier et al., 1978), as primary care physicians may be the first point of contact for those seeking help for a wide range of mental health concerns (Kroenke, Spitzer, Williams, Monohan, \& Lowe, 2007; Regier et al., 1978; Wang et al., 2005). Over half of undergraduates in one study indicated that they would choose to go to their local hospital in order to receive a referral to specialty mental health treatment (Lipscomb \& Shelly, 2004). This suggests that physicians frequently encounter patients with a mental health concern and may function as gatekeepers as those given authority 
to provide referrals for additional mental health treatment (Schurman, Kramer, \& Mitchell, 1985).

Given their important role as gatekeepers of mental health treatment, it may be significant to examine factors that influence the effectiveness of physicians' referrals in encouraging patients toward mental health treatment. Failing to connect patients who have a mental health concern to adequate care can lead to negative outcomes (Simon et al., 1995; Spitzer et al., 1995). Treating a patient diagnosed with depression almost doubles the overall cost of healthcare compared to a patient without depression (Simon et al., 1995). In addition, when compared to primary care patients without a mental health concern, primary care patients with a mental health concern report increased pain, greater impairment in physical functioning, greater interference with work or school, and decreased social activities (Spitzer et al., 1995). Clearly, leaving psychological problems untreated can be detrimental for patients and healthcare organizations.

Increasing the effectiveness of mental health treatment recommendations may be more relevant now than ever before as mental health screening tools and mental health professionals are becoming more accessible to physicians. Primary care physicians clearly have access to patients who have mental health concerns (Lipscomb \& Shelly, 2004) and most physicians appear willing to connect patients to appropriate mental health treatment (Cunningham, 2009; Deans \& Skinner, 1992). Additionally, a variety of succinct and efficient mental health screening tools have been developed to detect mental health concerns such as depression, post-traumatic stress disorder, and substance abuse problems (Brown \& Rounds, 1995; Cameron \& Gusman, 2003; Kroenke, Spitzer, \& Williams, 2001). However, medical providers have justifiably expressed that multiple barriers stand in the way of referring patients to mental health treatment (Cunningham, 2009). One of the barriers encountered by physicians is a shortage of accessible 
mental health providers (Cunningham, 2009). Fortunately, integrated behavioral health (IBH) care models are becoming more common in primary care settings. In IBH care models, individuals trained specifically in mental health are readily accessible to medical providers (Berge et al., 2017). Since primary care physicians and mental health service providers are collaborating with one another in these integrated care models, medical providers have more opportunities to recommend mental health treatment. Because of this, it is worthwhile to investigate how health care providers should frame the way they talk about mental health care and whether primary care physicians are an effective source to recommend mental health treatment. The results of this study can inform the way IBH models utilize physicians to encourage mental health treatment.

While a great deal of research has examined how physicians can increase compliance with physical health behavior recommendations such as adhering to medication and appointment keeping (Zolnierek \& Dimatteo, 2009), less is known about factors that influence patient adherence to physicians' mental health treatment referrals. Therefore, the present research tested factors that are theoretically linked to compliance in a primary care setting — authority (Redelmeier \& Cialdini, 2002) and message framing (Gallagher \& Udegraff, 2011). Understanding relevant factors that increase compliance with physicians' mental health treatment referrals may help promote and increase the percentage of patients who receive adequate mental health care.

\section{Compliance}

Compliance refers to an acquiescence to a request (Cialdini \& Trost, 1998). For example, if a physician recommends that a patient attends an appointment with a mental health professional to discuss his or her depressive symptoms, compliance would be displayed if the 
patient follows the physician's recommendation regardless of the patient's feelings about seeking mental health treatment. Cialdini and Goldstein (2002) delineated six overarching principles of social influence that can increase compliance: liking, reciprocation, consistency, scarcity, social validation, and authority (Cialdini \& Goldstein, 2002). The liking principle suggests that people will comply more if a request has been made by someone who they find physically attractive, similar to them, or cooperative (Cialdini \& Rhoads, 2001). Secondly, it has been demonstrated that people will act favorably and comply with a person's request if that person has acted favorably to them in the past, which is referred to as the reciprocity principle (Cialdini \& Goldstein, 2002). The consistency principle suggests that individuals will try to uphold prior commitments, behaviors, and attitudes when deciding if they should comply to a request (Cialdini and Trost, 1998). Additionally, the scarcity principle asserts that when items, products, opportunities, or chances are limited to a small supply, individuals will desire these items more and be more likely to comply with messages that encourage purchasing or consuming these products (Cialdini \& Goldstein, 2002). People also commonly look at others around them to decide how to think, feel, or behave and a person is more likely to comply to a request if others around them are behaving in the same way. This principle of influence is referred to as social validation (Cialdini \& Goldstein, 2002). The final principle of influence is the authority principle, which asserts that people often comply with requests that have been made by an expert or powerful source (Cialdini \& Goldstein, 2002).

\section{Authority and Compliance}

The authority principle is of particular interest in this study because physicians are usually perceived as experts (Jones, Sinclair, \& Courneya, 2003; Jones, Sinclair, Rhodes, \& Courneya, 2004; Wrench \& Butterfield, 2009), and they are perceived to hold high social status 
(Goodyear-Smith \& Buetow 2001). This indicates that physicians may wield two types of authority: expert and legitimate (cf. French \& Raven, 1959). Whereas authority due to expertise refers to social influence as a result of one's expert knowledge in a particular area, legitimate authority refers to influence as a result of one's position in a social hierarchy (Cialdini \& Goldstein, 2004; Raven, 2008).

Various studies suggest that as perceived authority increases, compliance increases as well, even in naturally occurring environments. For example, in 1974, Leonard Bickman conducted a study on a busy street in New York City. A male confederate was dressed either in regular civilian clothes, in a milkman's uniform, or as a guard. The confederate requested that participants engage in one of three tasks. Participants were either instructed to pick up a paper bag, give a dime to a stranger, or move away from the bus stop. Results of this study suggested that participants were more likely to comply with the request when the confederate was dressed as a guard (Bickman, 1974). Years later, the results of Bickman's study were replicated in Salt Lake City, Utah and St. Louis, Missouri (Bushman, 1984; Bushman, 1988).

In a replication study, Bushman (1984) observed 150 pedestrians in Salt Lake City, Utah. Wherein a male confederate was either dressed as a "bum" in old work shoes and greasy overalls, as a business executive in a two-piece business suit, or as a firefighter in a uniform. Forty-five percent of the participants completed the request when the confederate was dressed as a "bum", $50 \%$ of the participants completed the request when the confederate was dressed as a business executive, and $82 \%$ of the participants completed the request when the confederate was dressed in the firefighter uniform. Since both of these studies were conducted using a male confederate, a similar third study was conducted using a female confederate (Bushman, 1988). In a similar experimental design, a female confederate made the requests either dressed as a pan- 
handler, a business woman, or in a navy-blue uniform with a gold badge. Fifty-two percent of participants completed the request of giving the experimenter a dime when the confederate was dressed as pan-handler, $48 \%$ of the participants completed the request when she was dressed as a business woman, and $72 \%$ completed the request when she was dressed in the uniform (Bushman, 1988). Despite gender differences of the confederate, all three of these field studies suggest that as perceived authority increases, compliance increases as well.

Authoritative sources can increase compliance even when the requested behavior is detrimental to another person (Karakostas \& Zizzo, 2014; Milgram, 1978). In Stanley Milgram's seminal study on obedience, a type of compliance, participants were told by the experimenter to administer electric shocks to a confederate if the confederate answered a question incorrectly. The participants administering the shocks were unaware that the other participant was an actor and was not actually receiving the shocks. The participants were instructed to increase the voltage of the electric shock for every missed answer. The results of this study showed that approximately $60 \%$ of the participants complied when asked to administer the maximum voltage shock. In a more recent study, researchers asked participants to engage in an experimental game where they were requested by an authority figure to destroy another participant's earnings (Karakostas \& Zizzo, 2014). Approximately $60 \%$ of the participants engaged in the requested behavior even though it was harmful to another participant (Karakostas \& Zizzo, 2014). In both of these studies, authority figures were able to influence participants to comply with behaviors even if those behaviors were anti-social.

\section{Authority and Compliance with Health Behavior Recommendations}

Though no research to date has experimentally manipulated perceptions of authority on mental health treatment recommendations, research regarding physical health behavioral 
recommendations provide a close analog. This research has demonstrated that authoritative sources may increase patient's compliance with health behavior recommendations (Meulenaer et al., 2017; Olynick et al., 2017). In a study that relied on self-reported rates of compliance from patients, results indicated that patients' self-reported behavioral compliance with medication recommendations was positively correlated with their satisfaction with their physician's level of expertise (Olynick et al., 2017).

Mediating variables of perceived authority have also been examined, such as selfefficacy, i.e. one's own perceived ability to successfully engage in the coping response (Meulenaer et al., 2017). This may be particularly relevant given that help-seeking behavior itself may be conceptualized as a coping resource (Nadler, 1990). That is to say, authoritative sources may exert compliance behaviors because they increase patients' coping self-efficacy. In a sample of 816 participants from Belgium and Ireland, researchers warned participants about a fictitious mosquito. Researchers manipulated source expertise by having a doctor deliver the health message in the high expertise condition and a patient deliver the message in the low expertise condition. The results of this study suggest that the high expertise source significantly increased compliance via self-efficacy (Meulenaer et al., 2017). High perceived source expertise likely increased the participant's belief that he or she can effectively use the recommended solution which ultimately increased compliance (Meulenaer et al., 2017). The results of this study suggest that expert authority sources can increase compliance but may do so through changing selfrelevant beliefs.

Expert authority sources can have varying effects on attitudes towards and intentions to comply with online health messages (Hu \& Sundar, 2010; Kareklas et al., 2015). In one study, an electronic public service announcement either advocating or discouraging the use of vaccinations 
was shown to 272 participants (Kareklas et al., 2015). Participants were asked to provide their attitudes towards and behavioral intentions to vaccinate themselves as well as their family members after viewing the public service announcement. The public service announcement was accompanied by a comment written by either a doctor, a lobbyist, or a high school student (Kareklas et al., 2015). A short description of the comment writer was included as well. The description either read, "a medical doctor specializing in infectious disease and vaccinology”, "a professional lobbyist specializing in health care issues" or "a full-time undergraduate student majoring in English literature" for the doctor, lobbyist, and high school student commenters, respectively (Kareklas et al., 2015). Results of the study suggest that the doctors' online comments significantly increased participants' vaccination attitudes and behavioral intentions (Kareklas et al., 2015). These results indicate that a doctor's authority can influence intentions to comply with health behaviors even when the message is delivered using online platforms. Contrary to this evidence, other research suggests that in some conditions, health messages can be perceived as more credible when they are attributed to a lay person instead of a doctor (Hu \& Sundar, 2010) suggesting that doctors may not always be viewed as an authority or their authority status can have little influence on compliance.

In some situations, source expertise may not lead to increased health behavior compliance (Falomir-Pichastor, Butera, \& Mugny, 2002). That is to say, individual differences may moderate the effect of perceived authority on compliance. In a sample of 70 tobacco smokers, participants were asked to read an anti-smoking message either attributed to a high expertise source or a low expertise source. Participants were then asked to list all of the reasons why they engage in smoking. Researchers then randomly told participants that they either provided sufficient justification or insufficient justification for smoking (Falomir-Pichastor et al., 
2002). In this study, actual compliance was not measured but intentions to quit smoking were examined. When participants were told that he or she had insufficient reasons to smoke, the low expertise source had significantly more influence on the participant's intentions to quit smoking than the high expertise source. When a participant was told that he or she had sufficient reasons to smoke, the high expertise source tended to increase intentions to quit smoking, but this finding did not reach statistical significance (Falomir-Pichastor et al., 2002). Even though this study did not measure behavioral compliance, the results still suggest that individual factors such as a person's perception of whether their behavior is justified may moderate the effects of an expert source.

Cigarette use has been studied by other researchers as well. Researchers have examined how varying sources of information influence participant's attitudes towards electronic cigarette use (Case et al., 2018). Expertise and trustworthiness have been identified as two factors that contribute to a source's level of credibility (Pornpitakpan, 2004). Because of this, the researchers in this study measured participant's perception of trustworthiness for a variety of message sources including electronic cigarette companies, medical doctors, and government health agencies. The results of the study suggest that participants perceived electronic cigarettes to be less harmful and less addictiveness as their trust in the electronic cigarette companies increased suggesting that source credibility can influence attitude towards smoking behavior.

A message source's status as an expert authority often increases actual compliance, behavioral intentions to comply with, or behavioral attitudes towards complying with behavior recommendations (Case et al., 2018; Meulenaer et al., 2018; Kareklas et al., 2015; Olynick et al., 2017). However, an expert authority's level of persuasiveness may vary in some circumstances (Falomir-Pichastor et al., 2002; Hu \& Sundar, 2010). Mixed evidence suggests that more 
research should be conducted to identify how authoritative sources influence attitudinal, intentional, and behavioral reactions to messages that encourage help-seeking for mental health concerns.

\section{Authority and Compliance with Mental Health Treatment Recommendations}

A doctor's authority has been shown to increase compliance with some physical health recommendations, but it is uncertain whether this authority can overcome barriers such as stigma and encourage compliance with mental health treatment referrals. One study conducted in Australia examined the effectiveness of a school-based intervention designed to increase student's visits to their general practitioner for treatment of physical as well as mental health concerns (Wilson, Deane, Marshall, \& Dalley, 2008). In school settings, medical doctors delivered presentations that normalized visiting a doctor for mental health concerns, described how doctors could treat mental health concerns, and discussed how to overcome previous negative experiences when deciding to visit a doctor (Wilson et al., 2008). The results indicate that help-seeking intentions and actual appointments for a psychological problem significantly increased after the participants viewed the presentations (Wilson et al., 2008). Wilson and colleagues successfully demonstrated that a physician can increase mental health treatment seeking simply by providing information. Importantly however, the recommended treatment option during this program was for participants to seek help from a general practitioner, and not a professional trained directly in a mental health field such as a licensed counselor, psychologist, or behavioral health specialist. Future research should investigate whether medical doctors can increase compliance with referrals to treatment providers that are trained to target mental health concerns such as specialty mental health care providers, but also behavioral health consultants staffed in primary care settings. 


\section{Message Framing and Compliance}

Health behavior messages can be delivered by a variety of sources and also in a variety of formats. Studying the persuasiveness of message formats may help authorities increase compliance with health behavior recommendations. Changing the wording of health behavior messages is referred to as message framing (Wilson, Purdon, \& Wallston,1998). Framing messages in terms of gains or losses are two common manipulations that can be applied to health behavior communications (Banks et al., 1995; Wilson et al., 1998). Gain-framed messages, commonly referred to as positively framed messages, emphasize the benefits of performing a health behavior (Banks et al., 1995; Block \& Keller, 1995). Alternatively, loss-framed messages, commonly referred to as negatively framed messages, emphasize the risks of not performing a health behavior (Banks et al., 1995; Block \& Keller, 1995).

In a meta-analysis reviewing data from 165 studies with a total of 50,780 participants, neither gain-framed or loss-framed messages were found to be more persuasive or effective at inducing compliance (O'Keefe \& Jensen, 2006). The outcome variables considered in these studies included: behavioral attitude, behavioral intention, and actual behavior (O'Keefe \& Jensen, 2006). However, a second meta-analysis revealed that after considering the type of behavior being recommended, gain-framed messages appear to be superior (Gallagher \& Updegraff, 2011).

An important moderator to consider when evaluating the persuasiveness of gain vs. lossframed messages is the type of behavior that is being recommended. Two main types of health behaviors have been identified: illness prevention and illness detection (Gallagher \& Updegraff, 2011; O'Keefe \& Jensen, 2006). Illness prevention behaviors are behaviors that reduce a person's risk of developing an illness. These behaviors are usually not considered risky and may 
include activities such as: smoking cessation, skin cancer prevention such as wearing sunscreen, and physical activity (Gallaher \& Updegraff, 2011). Contrary, illness detection behaviors involve behaviors that would identify illnesses and include HIV testing and mammograms. These behaviors are typically considered riskier than illness prevention behaviors because a person may be informed that he or she has contracted a serious illness.

Gain-framed messages appear to be more persuasive than loss-framed messages when recommending illness prevention behaviors (Gallagher \& Updegraff, 2011; O'Keefe \& Jensen, 2006). Gain-framed messages may be more successful at eliciting compliance with illness prevention messages because they have been shown to increase the receiver's self-efficacy and be more memorable than loss framed messages (Gallagher \& Updegraff, 2011). When O'Keefe and Jensen (2006) observed the effects of message framing on a combined outcome measure of attitudes, intentions, and behaviors they found that gain-framed messages were more persuasive than loss-framed messages at recommending illness prevention behaviors. However, when considering the effects of message framing on behaviors apart from attitudes and intentions, gain-framed messages were more likely than loss-framed messages to increase actual compliance behaviors when the recommended behavior was categorized as illness prevention, but no effects were found on attitudes and intentions (Gallagher \& Updegraff, 2011). Additionally, in later reviews the advantage of gain-framed recommendations appears to be quite small and may only apply to very specific behaviors such as dental hygiene (O'Keefe \& Jensen, 2007). When promoting low risk, illness prevention behaviors, gain-framed messages appear to be superior to loss-framed messages at increasing behavioral compliance, but the advantage may be small and may only apply to certain recommendations. 
While gain-framed messages appear to be slightly more persuasive at recommending illness prevention behaviors, loss-framed messages may be more persuasive at recommending certain illness detection behaviors. In a meta-analysis of 53 studies, loss framed messages were shown to be more persuasive than gain- framed messages at recommending breast-cancer screening behaviors but no other illness detection behaviors (O'Keefe \& Jensen, 2009). Future research found that as a women's perceived risk of having breast cancer increased, the persuasiveness of loss-framed over gain-framed messages increased as well (Gallagher, Updegraff, Rothman, \& Sims, 2011). These results may give some evidence that loss-framed messages become more persuasive as susceptibility to an illness increases. However, while lossframed messages appear to be successful at recommending breast cancer detection behaviors, loss-framed messages do not appear to have any practical advantage over gain-framed messages when recommending other detection behaviors (Gallagher \& Updegraff, 2011; O'Keefe \& Jensen, 2006: O'Keefe \& Jensen, 2009).

The current study was interested in investigating the effects of message framing on messages that advocate the use of mental health services. Mavandadi and colleagues conducted one study observing the effects of message framing on mental health service recommendation compliance. Participants were exposed to specialty mental health care referral messages (Mavandadi et al., 2017). These messages were either neutral, gain-framed, or loss-framed. Gainframed messages discussed the positive outcomes of meeting with a mental health provider, the loss-framed messages discussed the negative aspects of not meeting with a mental health provider, and the neutral messages were a standard appointment reminder including the date and time or appointment, name of provider, and directions to the clinic location (Mavandadi et al., 2017). The messages that were framed in terms of gains significantly increased mental health 
treatment utilization when compared to the neutral messages (Mavandadi et al., 2017). While not statistically significant, gain-framed messages resulted in more appointment attendances than the loss-framed messages.

Some parallels between the physical health behavior literature and mental health behavior may be able to be drawn (Mavandadi et al., 2017). In the physical health behavior literature, gain- framed messages have been shown to induce greater levels of compliance with illness prevention behavior recommendations (Gallagher \& Updegraff, 2011; O’Keefe \& Jensen, 2006). Mavandadi et al. (2017) hypothesized that gain-framed messages were more persuasive in their study because, for these specific participants, attending an initial mental health appointment is more likely categorized as an illness prevention behavior. The researchers based this on the fact that detection of a mental health concern had already occurred before the participants read the referral messages because all of the participants attended a prior mental health assessment (Mavandadi et al., 2017). However, given that mental health service seeking is often stigmatized and seeking services may involve risk, it may not be appropriate to categorize mental health service seeking as an illness detection behavior in all scenarios. If mental health treatment is perceived as an illness prevention behavior instead of an illness detection behavior by treatment seekers, it is plausible that gain-framed messages may be slightly more effective at increasing compliance than loss-framed messages. Again, this advantage appears to be quite small and may not produce a significant effect. If treatment seekers do not perceive mental health treatment seeking as either an illness prevention or illness detection behavior, it is difficult to predict the influence of message framing on compliance. 


\section{Authority, Message Framing, and Compliance}

The relations between authority, message framing, and compliance is uncertain, and the literature is not consistent. In one study assessing exercise attitudes, intentions, and behaviors researchers investigated the interaction effects of source expertise and message framing in a sample of 192 college students (Jones et al., 2003). Source expertise was manipulated by either having a medical doctor or a high school student deliver a message that advocated physical exercise (Jones et al., 2003). Messages in this study were either framed positively or negatively. Positively framed messages highlighted potential gains while negatively framed messages highlighted potential losses that could occur if the participant fails to engage in physical exercise (Jones et al., 2003). Exercise messages delivered by an expert source in positive frame led to the most positive intentions to engage in exercise (Jones et al., 2003). Most importantly, a significant source by frame interaction effect indicated that messages framed in a positive way and delivered by an expert source resulted in the highest frequency of actual exercise behavior (Jones et al., 2003). Intriguingly, attitudes towards exercise showed no significant differences between conditions (Jones et al., 2003). Researchers hypothesized that the persuasive messages would impact exercise intentions and behaviors through attitudinal processes, but the results suggest that exercise behavior change occurred without any attitude change (Jones et al., 2003). Researchers speculate that exercise intentions and behavior may have been influenced by subjective norms, the perceived social pressure to engage in exercise, instead of attitudes (Jones et al., 2003). Despite no significant attitude change, this study still suggests that when expert sources deliver exercise promotion messages in a positive frame, exercise behavior is increased. However, in a replication study, results indicated no source by frame interaction effects for 
exercise attitudes, intentions, or behaviors suggesting that a positive frame and credible source do not always increase compliance (Jones et al., 2004).

In 2006, a third study was conducted examining the effects of message framing and source credibility on attitudes towards and intentions to engage in exercise (Arora, Stonger, \& Arora, 2006). Participants were presented with messages that advocated physical exercise. In the high credibility source condition, the messages were attributed to experts from the American Heart Association. In the low credibility source condition, the messages were attributed to "two individuals from the Midwest" (Arora, 2006). Messages regarding exercise were either framed in terms of gains or losses. Researchers found a main effect of source credibility on both attitudes towards exercise and intentions to engage in exercise (Arora, 2006). The high credibility source was more persuasive and induced the most positive attitudes towards and intentions to engage in exercise. No significant main effects for framing were found but a significant source by frame interaction was found for both attitudes and intentions (Arora, 2006). Contrary to results found by Jones and colleagues (2003), credible sources delivering messages in a negative frame, as opposed to a positive frame, resulted in the most positive attitudes towards and intentions to engage in exercise (Arora, 2006). The research on message framing, source credibility, and compliance is clearly mixed and inconclusive suggesting that more research should be conducted in this area.

\section{The Current Study}

\section{Purpose}

The purpose of this study was to examine the influence of perceived source authority and message framing on compliance with mental health treatment referrals in a sample of college students. Understanding how authoritative sources and message framing influence attitudes and 
intentions towards mental health treatment seeking could help increase mental health treatment utilization which may ultimately decrease health care costs and increase the quality of life for those that are experiencing a mental illness or mental health concern. The present study assessed attitudes and intentions toward mental health treatment seeking as a proxy for compliance. Because psychological distress and previous help-seeking have been linked to help-seeking attitudes (Lannin et al., 2016) and intentions to seek help (Lannin, Vogel, Brenner, \& Tucker, 2015), these variables were included as covariates.

In addition to observing the independent variables influence on attitudes and intentions to seek psychological help, the current study also examined whether source authority and message framing influence the likelihood that an individual will request initial counseling information. Attitudes and intentions have often been conceptualized as variables that are relevant to predicting the performance of actual help-seeking behaviors and have often served as a proxy for help-seeking research (Lannin et al., 2015); however, a weakness of the literature is that actual help-seeking decisions and behaviors have often not been measured (Lannin et al., 2016). Behavioral attitudes are the favorable or unfavorable evaluation of a behavior (Ajzen, 1985); whereas intentions reflect the reasoned and planful decision-making processes that precede a behavior (Ajzen, 1991). Both attitudes and intentions related to a behavior may therefore influence the initiation of a particular behavior (Rothman, 2000). However, intentions may be a more proximal predictor of actual help-seeking behaviors. That is, behavioral attitudes have been shown to influence intentions to seek mental health treatment (Li, Dorstyn, \& Denson, 2014) and actual initial help-seeking behaviors such as requesting information about counseling (Lannin et al., 2015), and utilizing mental health services (Bonabi et al., 2016). Additionally, intentions 
have been shown to increase behavioral initiation for a variety of health-related behaviors such as contraceptive use, sunscreen use, helmet use, and smoking cessation (Webb \& Sheeran, 2006).

\section{Hypotheses}

Source Effects on Attitudes, Intentions, and Help-seeking Decisions. Overall, it was expected that authoritative sources would elicit more compliance with mental health treatment recommendations and that this would result in more positive feelings towards and a greater willingness to seek psychological help. This hypothesis is supported by findings that authoritative sources are associated with eliciting greater amounts of behavioral compliance with a variety of recommendations and requests (Bickman, 1974; Bushman, 1984; Bushman, 1988; Jones et al., 2003; Karakostas \& Zizzo, 2014; Meulenaer et al., 2017; Milgram, 1978; Olynick et al., 2017; Wilson et al., 2008). Therefore, it was hypothesized that participants who are exposed to a recommendation from an authoritative source (i.e., a medical doctor) would indicate a significantly higher increase in help-seeking attitudes, intentions to seek help, and initial decisions to seek counseling information, compared to those exposed to a recommendation delivered by a non-authoritative source (i.e., an undergraduate student), controlling for psychological distress and previous help-seeking behavior.

Interaction of Source and Message Framing. It was hypothesized that compliance and willingness to seek psychological help information will be influenced by the combined effects of source authority and message framing manipulations. Source by frame interactions have been shown to significantly influence rates of compliance with exercise recommendations (Arora, 2006; Jones et al., 2003). Significant interaction effects were observed in the high authority condition, but Jones and colleagues reported that the positive message frame was more effective while Arora (2006) found that the negative message frame was the most effective. Jones and 
colleagues (2003) indicated that when participants receive messages from authoritative sources in a positive frame as opposed to a negative frame, participants produce less counterarguments and have more positive thoughts about the recommended behavior. Since mental health service seeking is highly stigmatized, individuals who are considering seeking mental health treatment likely have counterarguments that are easily accessible. Because of this, it may be important for participants to be exposed to positive message framing that is less likely to elicit counterarguments. Therefore, in line with results of Jones and colleagues (2003), it was hypothesized that a significant source authority by message framing interaction will occur, wherein participants in the high authority + positive message condition will report the greatest increase in intentions to seek psychological help and decisions to seek counseling information, controlling for psychological distress and previous help-seeking behavior. 


\section{CHAPTER III: RESEARCH METHODOLOGY \\ Participants}

After obtaining IRB approval, 534 student participants were recruited from Illinois State University using SONA, the Psychology department's electronic participant pool. Out of the 534 recruited participants, 122 participants did not complete both the pretest and posttest surveys, so their data was removed from the final analysis, leaving 412 participants (77.2\%) who completed both pretest and posttest measures. Participant data $(n=8)$ was removed if the participant completed the posttest survey in under two minutes, or if participants took longer than one hour to complete the posttest survey $(n=6)$, or if the time between his or her pretest and posttest was not at least 24 hours $(n=125)$. The final sample consisted of 273 participants (female $=83.2 \%$; male $=15.4 \%$, mean age $=19.84, \mathrm{SD}=2.35$, range $=18-36$; year in school, first year $=41.8 \%$, second year $=13.9 \%$, third year $=22.7 \%$, fourth year $=19 \%$, graduate $=0.7 \%$; White $=75.25 \%$, Latino, or Latina $=13.6 \%$, African American or Black $=9.9 \%$, Asian American, Asian, or Pacific Islander $=3.7 \%$, Multiracial $=1.8 \%$, American Indian, Alaskan Native, or Hawaiian Native $=.4 \%)$.

\section{Measures}

\section{Demographic Questionnaire}

Participants completed a demographic questionnaire that gathered information about year in school, ethnicity, age, and sex.

\section{Psychological Distress}

Psychological distress was measured by the Kessler K6+ scale. The K6+ scale is a sixitem measure that asks participants to indicate how often they felt nervous, hopeless, restless, worthless, depressed, and whether "everything was effortful" in the past 30 days (Kessler et al., 
2002). Participants reported the frequency of these symptoms by indicating that they occur either: "all of the time", "most of the time", "some of the time", "a little of the time", or "none of the time". An item score ranging from 0-4 was assigned to each question. An answer of "all of time" was assigned a value of 4 , an answer of "most of the time" was assigned a value of 3 , an answer of "some of the time" was assigned a value of 2 , and an answer of "none of the time" was assigned a value 0 . A total K6+ score was obtained by summing the item scores. Possible scores range from 0 to 24 and higher scores indicate greater psychological distress while lower scores indicate less psychological distress. The K6+ has demonstrated strong internal consistency reliability $(\alpha=.89)$ (Kessler et al., 2002). The measure has also been shown to accurately classify serious mental illness (Kessler et al., 2003) as well as moderate mental illness (Prochaska et al., 2012) indicating that the measure can detect psychological distress caused by a variety of mental health disorders.

\section{Past Psychological Help-Seeking}

Past help seeking was assessed by asking participants, "As an adult, have you ever voluntarily visited a counselor or other mental health professional to discuss a mental health or emotional concern?" Participants then responded by indicating "yes" or "no". Participants were then either classified as either 1) having sought psychological help in the past or 2) having never sought psychological help in the past.

\section{Help Seeking Attitudes}

Help seeking attitudes were measured by the Mental Help Seeking Attitudes Scale (MHSAS) (Hammer, Parent, Spiker, \& Douglas, 2018). The MHSAS measured a participant's attitudes toward seeking professional mental health services using 9 items. Attitudes are defined as, a participant's "overall evaluation (good vs. bad) of the act of seeking help from a mental 
health professional" (Hammer et al., 2018). The MHSAS asked participants to indicate their opinion about mental health services after reading a prompt that states, "If I had a mental health concern, seeking help from a mental health professional would be...” (Hammer et al., 2018). Participants responded on a 7-point semantic differential scale. Each item consists of two polar adjectives such as "useless and useful", "good and bad", "satisfying and unsatisfying" allowing participants to indicate their attitudes toward help seeking on a continuum ranging from positive to negative (Hammer et al., 2018). A score from 1-7 was assigned to each item and item scores are then averaged to produce a total score ranging from 1-7. Higher scores indicate a more positive attitude toward help seeking while lower scores indicate a more negative attitude toward help seeking. Good test-retest validity has been established in a sample of adults from the United States at 3 weeks (.76) (Hammer et al., 2018). Hammer and colleagues (2018) also demonstrated strong internal consistency reliability $(\alpha=.92)$. In validity testing, Hammer and colleagues (2018) demonstrated evidence for convergent validity when data strongly correlated with other measures of help seeking attitudes such as the Attitudes Towards Seeking Professional Psychological Help Scale and the Psychological Openness subscale score of the Inventory of Attitudes Toward Seeking Mental Health Services (Hammer et al., 2018).

\section{Help Seeking Intentions}

Help seeking intentions were measured by the Mental Help Seeking Intention Scale (MHSIS) (Hammer \& Spiker, 2018). The MHSIS measured a participant's intentions to seek help from a mental health professional if he or she had a mental health concern (Hammer \& Spiker, 2018). The 3-item measure asked participants to rate their intentions to seek help on three separate 6-point Likert scales ranging from 1 to 7 . The first item stated, "If I had a mental health concern, I would intend to seek help from a mental health professional” (Hammer \& Spiker, 
2018). Possible answers ranged from 1 (extremely unlikely) to 7 (extremely likely) (Hammer \& Spiker, 2018). The second item stated, "If I had a mental health concern, I would try to seek help from a mental health professional" and participants indicated an intention from 1 (definitely false) to 7 (definitely true) (Hammer \& Spiker, 2018). The final item stated, "If I had a mental health concern, I would plan to seek help from a mental health professional" and participants responded from 1 (strongly disagree) to 7 (strongly agree) (Hammer \& Spiker, 2018). A total mean score was computed by averaging the item scores. Total scores ranged from 1 to 7 with higher scores indicating greater intentions to seek help from a mental health professional. Spike and Hammer (2006) report strong internal consistency reliability $(\alpha=.94)$. Additionally, the MHSIS has been shown to predict with 70\% accuracy actual help seeking behavior (Hammer \& Spiker, 2018).

\section{Decision to Seek Counseling Information}

To assess a participant's initial help seeking behavior, participants were asked, "Would you like additional information about ISU counseling services?". Participants were also asked, “Are you aware that ISU offers counseling services?” to control for the influence of participant's already possessing information about ISU counseling services.

\section{Study Design}

Independent variables for this study were source authority and message framing, covariates were psychological distress and past help seeking, and dependent variables were attitudes towards seeking mental health treatment, intentions to seek mental health treatment, and that rate at which participants request information about counseling services. Using a $2 \times 2$ 
between subject's design, participants were randomly assigned to 1 one of 4 experimental groups (see Figure 1).

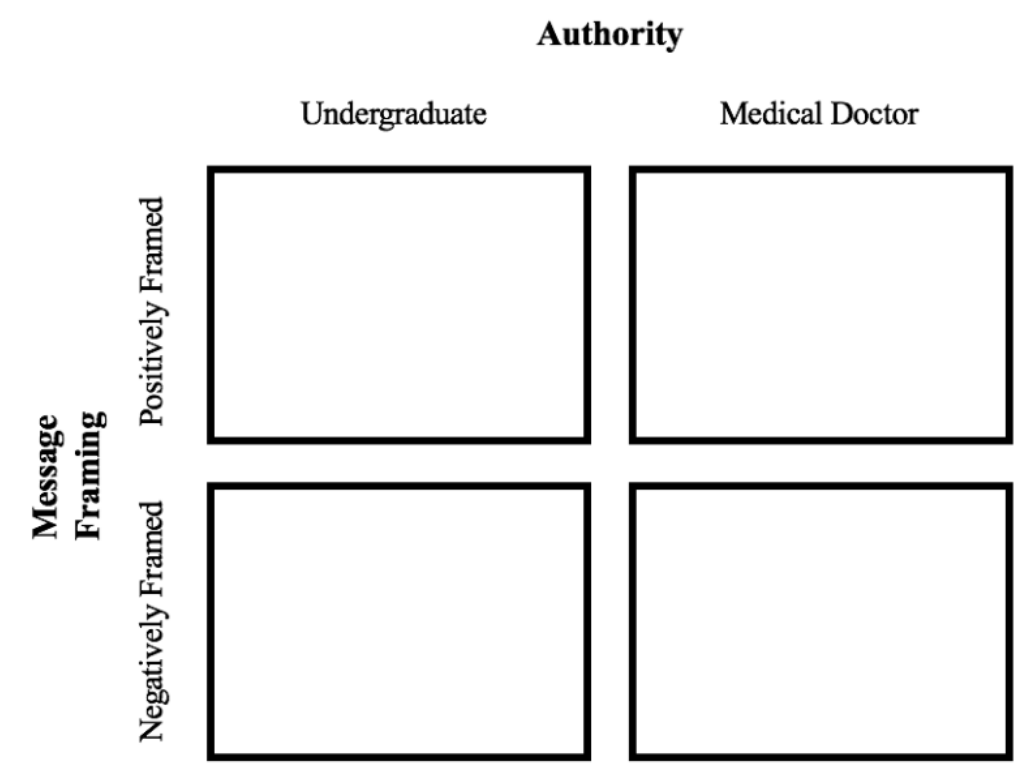

Figure 1. Four experimental conditions in which participants were assigned. Conditions include: an undergraduate source delivering a message in a positive frame, a medical doctor delivering a message in a positive frame, and undergraduate delivering a message in a negative frame, and a medical doctor delivering a message in a negative frame.

\section{Procedure}

The study was completed in two phases. After obtaining IRB approval, participants were recruited through SONA. During the first phase of the study, participants completed all of the measures electronically via Qualtrics software. Participants were asked to complete an informed consent form. Participants were then asked to complete the demographics questionnaire, the Kessler K6+, and answer questions regarding their past and current mental health care seeking. Participants also completed the Mental Help Seeking Attitudes Scale (MHSAS) and the Mental Help Seeking Intentions Scale (MHSIS) for pretest data. 
After completion of the pretest survey, participants were contacted via electronic mail and asked to complete the second phase of the study. Participants were then asked to complete the Kessler K6+ a second time. Upon the second completion of the Kessler K6+, participants received immediate score feedback. Researchers provided participants with their Kessler K6+ scores in order to make the study more realistic and personally relevant to the participants. In addition to receiving his or her individual scores, all participants read a message that states,

"Prior research has indicated: Scores below a 5 are usually indicative of lower levels of mental distress. Scores higher than or equal to 5, but lower than 13, usually indicates a moderate level of distress. About $28 \%$ of the population scores in this range. If you scored in this range you could likely benefit from consulting with a mental health professional-such as a psychologist, psychiatrist, or mental health counselor - to see if you could benefit from treatment. Scores equal to or higher than 13 usually indicate that you may be experiencing a more severe level of distress. About 6\% of the population scores in this range. If you scored in this range, you would likely benefit a great deal from seeking help from a mental health professional-such as a psychologist, psychiatrist, or mental health counselor Note: the scores are based on your own self-reported distress, and do not constitute a professional diagnosis or professional advice concerning mental health treatment."

Participants were then randomly assigned via survey software to one of four different mental health treatment referral messages. The perceived authority factor manipulated the identity of the message source. In both the high authority and low authority conditions, participants were asked to "imagine" that he or she was experiencing a mental health concern when reading the mental health treatment recommendation.

\section{High Authority}

In the high authority group, the source of the message was identified as a medical doctor.

The message source was introduced with text that read,

For this next part, please imagine that you are talking to a MEDICAL DOCTOR. Medical doctors are individuals who are trained to practice medicine and have a Doctor of Medicine degree. Imagine that you are talking to this medical doctor because you are struggling with a mental health concern. Try to put yourself in the position of someone who is trying to decide if they want to seek help from a mental health professional such 
as a counselor, psychologist, psychiatrist, or social worker. The medical doctor is recommending that you seek help from a mental health professional and says to you...

\section{Low Authority}

In the low authority group, the source of the message was identified as an undergraduate

student. The undergraduate student was introduced with text that read,

For this next part, please imagine that you are talking to an UNDERGRADUATE STUDENT. Undergraduate students are college or university students who have not received a bachelor's degree. Imagine that you are talking to this undergraduate student because you are struggling with a mental health concern. Try to put yourself in the position of someone who is trying to decide if they want to seek help from a mental health professional such as a counselor, psychologist, psychiatrist, or social worker. The undergraduate student is recommending that you seek help from a mental health professional and says to you...

The message framing factor manipulated the content of the treatment recommendation message and messages were framed either positively or negatively. The messages used in the current study were crafted based on literature evaluating formatting of framed messages and Flesch-Kincaid readability scores. Framed messages can be formatted in four different ways (Brujin, Out, and Rhodes, 2014; O'keefe \& Jensen, 2006). Brujin and colleagues (2014) provided examples of each category. The first category is positively framed messages combined with attained outcomes such as "sufficient exercise increases your chance to have a healthy heart". The second category is positively framed messages combined with avoided outcomes such as, "sufficient exercise decreases your chance of heart disease and heart failure." The third category is negatively framed messages combined with attained outcomes such as, "insufficient exercise increases your chance of heart disease and heart failure". The fourth and final category is negatively famed messages with avoided outcomes such as, "insufficient exercise decreases your chance to have a healthy heart". The type of outcome discussed in a message, (attained vs. avoided) has been referred to as the "kernel state" (O'keefe \& Jensen, 2006). Researchers 
showed that after evaluating 165 messages designed to promote physical activity, persuasiveness of the messages did not significantly differ if the message had attained, avoided, or combined kernel states (O’keefe \& Jensen, 2006). Brujin et al. (2014) experimentally manipulated messages and also observed no main effects for the type of kernel state on persuasiveness. Since both of these studies suggest persuasiveness is not influenced by kernel states, the current researcher chose to include both attained and avoided outcomes in the messages used in the current study in order to better mimic real-life experiences. The current researcher also crafted the messages used in this study to have similar readability levels. On the Flesch-Kincaid readability test, the messages used in the current study scored below a fifth-grade reading level with the positively framed message scoring a 4.5 and the negatively framed message scoring a 4.7. The researcher chose to use language below a fifth-grade level in order to increase participant understanding of the messages.

\section{Positively Framed Message}

In the positively framed message group, the referral message discussed the benefits of receiving mental health treatment. The positively framed message read:

Going to see a counselor is good and can make life more enjoyable. Going to see a counselor can make you want to spend time more with your friends and family.

Counseling can make it easier for you to go to work or school. Your body may feel better too. Seeing a counselor may also reduce your medical costs.

\section{Negatively Framed Message}

In the negatively framed message group, the referral message discussed the consequences of not receiving mental health treatment. The negatively framed message read:

Choosing not to go see a counselor is bad and can make life less enjoyable. Not going to see a counselor can make you want to spend less time with your friends and family. Not going to see a counselor can make it harder for you to go to work or school. Your body may feel worse too. Not going to see a counselor may also increase your medical costs. 
After reading the mental health treatment referral message, participants were asked to complete the MHSAS and the MHSIS a second time. Next, participants completed two questionnaires pertaining to source authority and message framing that were used as manipulation checks. For source authority, participants responded to one item that read, "The treatment recommendation was provided by a knowledgeable, credible, and authoritative source." Participants responded on a 5-point Likert scale with answers ranging from strongly disagree to strongly agree. For message framing, participants assessed whether the referral message emphasized the benefits of seeking mental health treatment or the costs of not seeking mental health treatment. Participants rated two items on a 5-point Likert scale with answers ranging from strongly disagree to strongly agree. The items will read: "The mental health treatment referral emphasized the benefits of seeking treatment" and "The mental health treatment referral emphasized the consequences of not seeking treatment."

To assess decisions to seek counseling information, participants were then asked, "Are you aware that ISU offers free counseling services?" and "Would you like additional information about ISU counseling services?" Finally, participants were provided a debriefing statement to read. 


\section{CHAPTER IV: RESULTS}

Bivariate correlations and descriptive statistics are presented in Table 1.

\section{Descriptive Analyses}

K6+ pretest scores for the present sample indicated that of the 273 participants who completed the measure, $28.9 \%$ of the sample reported low distress (scores in the range of 0-4), $52.7 \%$ reported moderate distress (scores in the range of 5-12), and $18.3 \%$ of the sample reported severe distress (scores above 12). Additionally, of the 272 participants who indicated their past help seeking behavior, $42.9 \%$ reported that they have talked to a mental health professional about a mental health concerns while $56.8 \%$ reported that they have not talked to a mental health professional about a mental health concern in the past.

\section{Manipulation Checks}

An independent samples t-test was conducted to evaluate the effectiveness of the source authority manipulation. The difference between credibility ratings of those rating the doctor $(M=$ 3.99, $S D=0.96$, Range: $1-5)$ and those rating the undergraduate $(M=3.70, S D=1.67$, Range: 1 - 5) was statistically significant, $t(271)=-2.24, p=.026$. This indicates that students perceive doctors as a slightly more authoritative source than undergraduates.

Two independent samples t-tests were conducted to evaluate the effectiveness of the message framing manipulation. The first manipulation check item asked participants to rate how much the message emphasized the benefits of seeking counseling services. The difference between ratings of the message's emphasis on benefits of those rating the negatively framed message $(M=3.37, S D=1.42$, Range: $1-5)$ and those rating the positively framed message $(M$ $=4.56, S D=0.62$, Range: $2-5$ ) was statistically significant $t(271)=-8.62, p=.000$. The second manipulation check item asked participants to rate how much the message emphasized the 
consequences of not seeking counseling services. The difference between ratings of the message's emphasis on consequences of those rating the negatively framed message ( $M=3.81$, $S D=1.26$, Range: $1-5)$ and those rating the positively framed message $(M=2.47, S D=1.19$, Range: $1-5)$ was statistically significant $t(270)=9.01, p=.000$. This indicates that students perceived the positively framed message as placing a stronger emphasis on the benefits of seeking counseling and the negatively framed message as placing a stronger emphasis on the consequences of not seeking psychological services.

\section{Main Analyses}

Hypothesis one predicted that participants who are exposed to a recommendation from an authoritative source (i.e., a medical doctor) would indicate a significantly higher increase in helpseeking attitudes, intentions to seek help, and initial decisions to seek counseling information, compared to those exposed to a recommendation delivered by a non-authoritative source (i.e., an undergraduate student), controlling for psychological distress and previous help-seeking behavior. To test this hypothesis, a repeated measure analysis of covariance (ANCOVA) was conducted in which source authority was the independent variable, psychological distress and past help seeking were covariates, and attitudes towards and intentions to seek psychological help were the dependent variables. Interaction effects for the ANCOVA were also calculated, as can be seen in Table 2 and Table 3. A hierarchical multiple logistic regression test was conducted to examine the effects of source authority on the likelihood of requesting counseling health information. In this analysis, the decision to request counseling information was specified as the dependent variable. To examine hypothesis one, the covariates of psychological distress, past help seeing (coded such that $0=n o$ and $1=y e s$ ), and awareness of university counseling 
services were entered first and then source authority (code such that $0=$ undergraduate student and $1=$ doctor ) was entered.

Hypothesis one was not supported by the data because individuals in the high authority source did not indicate significantly higher attitudes towards, intentions to seek psychological help, or decisions to seek counseling information than those in the low authority source, when controlling for psychological distress and past help seeking. When controlling for psychological distress and past help seeking, there was not a statistically significant main effect of source authority on attitudes towards seeking psychological help, $F(1,266)=.87, p=.352$, partial $\eta^{2}=$ .00 , or on intentions to seek psychological help, $F(1,266)=1.03, p=.312$., partial $\eta^{2}=.00$. As shown in Table 4, results of the logistic regression indicated that source authority was not statistically significant predictor of decisions to seek counseling information $b=0.07, S E=0.36$, $e^{b}=1.08,95 \%$ CI for $\mathrm{OR}=[0.54,2.17]$.

Hypothesis two predicted that a significant source authority $\times$ message framing interaction will occur, wherein participants in the high authority and positive message condition will report the greatest increase in intentions to seek mental health treatment and decisions to seek counseling information, controlling for psychological distress and previous help-seeking behavior. The ANCOVA analyses described above included the relevant results about potential interaction effects of the independent variables on attitudes and intentions. However, to examine decisions to seek counseling information, message framing (coded such that $0=$ negative and $1=$ positive) was first entered into the logistic regression described above along with source authority and the covariates described above, and lastly the interaction term of source authority ×message framing was entered. 
Hypothesis two was not supported by the data because individuals in the high authority and positive message framing condition did not indicate significantly higher intentions to seek psychological help or decisions to seek counseling information when controlling for psychological distress and past help seeking. As shown in Table 3, There was no statistically significant interaction between source authority and message-framing on intentions to seek psychological help, when controlling for psychological distress and past help seeking $F(1,266)=$ $.770, p=.381$, partial $\eta 2=.003$. As shown in Table 4, the Source Authority $\times$ Message Framing interaction term was also not statistically significant predictor of decisions to seek counseling information, $b=.196, S E=.713, \mathrm{e}^{\mathrm{b}}=1.217,95 \% \mathrm{CI}$ for $e^{\mathrm{b}}=[.30,4.93]$ 
Table 1.

Correlations, Means, and Standard Deviations for Study Variables

\begin{tabular}{|c|c|c|c|c|c|c|c|c|c|c|c|}
\hline Variable & 1 & 2 & 3 & 4 & 5 & 6 & 7 & 8 & 9 & 10 & 11 \\
\hline 1. Source & - & .03 & .03 & 05 & -.06 & -.02 & .02 & -.04 & -.08 & -.02 & .03 \\
\hline 2. Frame & .03 & - & .08 & .04 & .02 & -.07 & .07 & .02 & .00 & -.03 & .07 \\
\hline 3. Past Help Seeking & .03 & .08 & - & $.20^{* *}$ & $.15^{*}$ & $.27^{* *}$ & $.20^{* *}$ & $.17^{* *}$ & $.27^{* * * *}$ & $.26^{* * *}$ & .07 \\
\hline 4. Pretest Distress & .05 & .04 & $.20^{* *}$ & - & -.03 & $-.13^{*}$ & $.82^{* * *}$ & $-.16^{*}$ & $-.17^{* * *}$ & .10 & $.16^{* *}$ \\
\hline 5. Pretest Help Seeking Attitudes & -.06 & .02 & $.15^{*}$ & -.03 & - & $.67^{* * *}$ & -.04 & $.79^{* * *}$ & $.64^{* * *}$ & .80 & .11 \\
\hline 6. Pretest Help Seeking Intentions & -.02 & -.07 & $.27^{* * *}$ & $-.13^{*}$ & $.67^{* * *}$ & - & $-.14^{*}$ & $.64^{* * *}$ & $.80^{* * * *}$ & $.13^{*}$ & .07 \\
\hline 7. Posttest Distress & .02 & .07 & $.20^{* *}$ & $.82^{* * * *}$ & -.04 & $-.14^{*}$ & - & -.11 & $-.17^{* *}$ & .10 & $.19^{* *}$ \\
\hline 8. Posttest Help Seeking Attitudes & -.04 & .02 & $.17^{* *}$ & $-.16^{*}$ & $.79^{* * * *}$ & $.64^{* * *}$ & -.11 & - & $.71^{* * * *}$ & .02 & $.16^{* *}$ \\
\hline 9.Posttest Help Seeking Intentions & -.08 & .00 & $.27^{* * * *}$ & $-.17^{* *}$ & $.64^{* * *}$ & $.80^{* * * *}$ & $-.17^{* *}$ & $.71^{* * * *}$ & - & .10 & .06 \\
\hline 10. Awareness of Counseling & -.02 & -.03 & $.26^{* * *}$ & .10 & .08 & $.13^{*}$ & .10 & .02 & .10 & - & -.03 \\
\hline 11. Seeking Counseling Information & .03 & .07 & .07 & $.16^{* *}$ & .11 & .07 & $.19^{* *}$ & $.16^{* *}$ & .06 & -.03 & - \\
\hline Means & .51 & .45 & .43 & 8.20 & 5.85 & 5.01 & 7.57 & 5.83 & 5.07 & .92 & .15 \\
\hline Standard Deviations & .50 & .50 & .50 & 5.38 & 1.13 & 1.61 & 5.35 & 1.15 & 1.60 & .27 & .36 \\
\hline
\end{tabular}

Note. $* p<.05, * * p<.01, * * * p<.001$ 
Table 2.

Analysis of Covariance Summary on Attitudes Towards Seeking Psychological Help

\begin{tabular}{ccccccc}
\hline Variable & Sum of Squares & $d f$ & Mean Square & $F$ & $p$ & $\eta 2$ \\
\hline Distress & 7.86 & 1 & 7.86 & 3.47 & .064 & .01 \\
Past Help Seeking & 21.88 & 1 & 21.88 & 9.70 & .002 & .04 \\
Frame & .08 & 1 & .08 & .03 & .855 & .00 \\
Source & 2.00 & 1 & 2.00 & .87 & .352 & .00 \\
Frame X Source & .36 & 1 & .36 & .16 & .692 & .00 \\
Error & 600.52 & 266 & 2.26 & & & \\
\hline
\end{tabular}

Table 3.

Analysis of Covariance Summary on Intentions to Seek Psychological Help

\begin{tabular}{cccccccc}
\hline Variable & Sum of Squares & df & Mean Square & F & $p$ & $\eta 2$ \\
\hline Distress & 60.34 & 1 & 60.34 & 14.72 & .000 & .05 \\
Past Help Seeking & 135.90 & 1 & 135.90 & 33.16 & .000 & .11 \\
Frame & 2.76 & 1 & 2.76 & .67 & .413 & .00 \\
Source & 4.20 & 1 & 4.20 & 1.03 & .312 & .00 \\
Frame X Source & 3.16 & 1 & 3.16 & .77 & .381 & .00 \\
Error & 1090.34 & 266 & 4.10 & & & \\
\hline
\end{tabular}


Table 4.

Hierarchical Logistic Regression Analysis for Variables Predicting Decisions to Seek Counseling Information

\begin{tabular}{lrrrrrr}
\hline & \multicolumn{5}{c}{ Model 1 } & \multicolumn{3}{l}{ Model 2 } \\
\cline { 2 - 7 } \multicolumn{1}{c}{ Variable } & $b$ & $S E$ & OR $\mid 95 \%$ CI for OR & $b$ & $S E$ & OR $\mid 95 \%$ CI for OR \\
\hline Past Help Seeking & .23 & .38 & $1.25 \mid .60,2.62$ & .23 & .38 & $1.25 \mid .60,2.62$ \\
Awareness & -.60 & .65 & $.56 \mid .16,1.97$ & -.60 & .65 & $.55 \mid .15,1.96$ \\
Distress & 1.01 & .27 & $2.8 \mid 1.63,4.64$ & 1.01 & .27 & $2.74 \mid 1.62,4.62$ \\
Frame & .32 & .36 & $1.38 \mid .69,2.76$ & .22 & .51 & $1.24 \mid .46,3.39$ \\
Source & .07 & .36 & $1.08 \mid .56,2.17$ & -.03 & .51 & $.97 \mid .36,2.65$ \\
Frame X Source & & & & .20 & .71 & $1.22 \mid .30,4.93$ \\
\end{tabular}

Note. OR $=$ Odds Ratio. Distress scores are standardized. Previous therapy is coded such that $0=$ no and $1=$ yes. Model 1 includes past psychological help seeking, awareness of counseling services, psychological distress, message frame, and source authority as predictor variables. Model 2 includes past psychological help seeking, awareness of counseling services, psychological distress, message frame, source authority, and message frame $X$ source authority as predictor variables. 


\section{CHAPTER V: DISCUSSION}

Mental health treatment has been established as an effective intervention for helping improve the quality of life of those struggling with a mental health concern (Spitzer et al., 1995). Despite its known effectiveness, the majority of individuals with a mental health concern still do not receive appropriate mental health treatment (Wang et al., 2005). Many researchers are aware of this discrepancy and have investigated ways to increase mental health treatment utilization. Researchers have often focused on reducing the stigma surrounding mental health treatment to increase utilization, but this approach has shown varying effectiveness (Griffiths et al., 2014). Instead of focusing on stigma reduction, the current study added to the body of literature by investigating how two strategies of persuasion, source authority and message framing, influence compliance with mental health treatment recommendations.

It was hypothesized that authoritative sources would significantly increase help-seeking attitudes, intentions to seek help, and initial decisions to seek counseling information. Results of the current study did not support this hypothesis. This finding differs from several studies that have shown that authoritative sources positively influence participants' attitudes towards engaging in health behaviors (Arora et al., 2006; Case et al., 2018; Kareklas et al., 2015) and studies that have shown that authoritative sources are more successful than non-authoritative sources at increasing intentions to engage in health behaviors (Arora et al., 2006; Jones et al., 2003; Kareklas et al., 2015). Null results in this study may have been observed due to ceiling effects on attitudes towards and intentions to seek psychological help. Both pretest attitudes towards and intentions to seek psychological help variables were measured on a scale of $1-7$. Results on the pretest attitudes towards seeking psychological help measure computed to a mean score of 5.85, a median score of 6.11, and a mode score of 7.00. Furthermore, $21.6 \%$ of the 
sample scored a 7 out of 7 on the attitudes towards seeking psychological help measure indicating that a large portion of the sample already held the most favorable attitudes towards seeking psychological help at pretest. A similar pattern was observed on the intentions to seek psychological help measure, which was also measured on a $1-7$ scale. Results on the pretest intentions to seek psychological help measure computed to a mean score of 5.01, a median score of 5.00, and a mode score of 7.00. On intentions to seek psychological help, $21.2 \%$ of the sample scored 7 out of 7 which indicates that a large portion of the sample had the most favorable intentions to seek psychological help at pretest. Due to most participants' scoring at the upper limits of each measure at pretest, authoritative sources were unlikely to increase attitudes towards and intentions to seek psychological help in a meaningful way. This observed ceiling effect may indicate that on average, college students in the present sample, did not demonstrate a particular need for interventions targeted at improving perceptions of psychological help. However, other subsamples of undergraduate students may hold worse attitudes and lower intentions to seek psychological help. It may be important for future researchers to identify why some students have negative perceptions of psychological help seeking while others have a positive view.

It was also hypothesized that an authoritative source delivering a message in a positive frame would significantly increase intentions to seek psychological help and the likelihood of seeking mental counseling information. Results did not support this hypothesis, which is inconsistent with the study conducted by Jones and colleagues (2003) that suggested that exercise recommendations delivered by an expert source in a positive frame led to the largest increases in intentions to exercise. Although inconsistent with results found by Jones and Colleagues (2003), these null results are consistent with Jones and Colleagues replication study 
conducted in 2004 that found no interaction effects of framing and source authority on exercise behaviors. Message framing manipulations may be insignificant when recommending mental health services because mental health treatment seeking may be different than other health behaviors because it cannot be easily classified as either an illness detection or illness prevention behavior. Mental health treatment seeking may warrant a unique classification due to the stigma associated with receiving mental health services (Corrigan, 2004; Vogel, Wade, \& Haake, 2006). Additionally, similar to the results regarding the first hypothesis, these null results may be also be contributable to observed ceiling effects on intentions to seek psychological help. Message framing and source manipulations Message framing effects may have also had no significant influence on decisions to seek mental health information because most students (91.9\%) were aware, prior to their participation in this study, that ISU offers free counselling services. Since most participants were aware the ISU offers counseling services, the messages used in the current study may not have offered any novel information to the participants. The messages in this study provided information about general life outcomes that may be obtained if someone seeks counseling or if someone chooses not to seek counseling. Because the information provided was quite general, the participants in the study may have already been aware of this information. The messages may have been stronger if participants were reading novel information. For example, participants are likely not aware of the percentage of people who benefit from treatment and therefore this type of information may have been led to a more persuasive message. Because the information may have been common knowledge to the participants, they may not have been motivated to change their attitudes, intentions, or decisions to seek information about counseling services. Overall, findings indicate that college students 
have most likely already been exposed to messages that bring awareness to psychological resources, making the present study's exposure less novel and impactful to them.

Despite not finding significant results for source authority or framing effects, the results of this study still have several implications. First, students viewed the doctor source as only slightly more credible than the undergraduate source indicating that college students may not view doctors as authoritative sources, especially regarding mental health information. It is logical to hypothesize that doctors may not be viewed as authoritative sources because college students on ISU's campus have access to free mental health services, and many may not need to receive a doctor's referral to take advantage of these services. However, for populations of people who have less knowledge about and less access to psychological services, a doctor's recommendations may be perceived as more credible. While medical doctors are usually viewed as experts and high authority sources, they may not have been viewed as highly authoritative in the current study because they may not be perceived as experts on mental health topics. Although research suggests that most people do seek mental health care from a medical doctor (Wang et al., 2005), it may not be the case that this occurs because medical doctors are perceived as experts in this area. Instead, the general medical sector may be the most often utilized treatment option for mental health concerns for other reasons such as accessibility, familiarity, or because it is less stigmatized. Nevertheless, the finding that undergraduates perceive doctors as less authoritative than expected may indicate why null results were obtained in this study and may be an interesting area for future research.

Second, another implication of this study may be that the persuasion strategies of message framing and authority may not be powerful enough to alter attitudes and intentions to seek psychological services, especially in online contexts. This may be true because people tend 
to view most online information as credible despite variations of perceived source credibility (Eastin, 2001). Other social influence strategies such as social validation may be more persuasive in online interventions. Social validation occurs when individuals perceive that are others are behaving in similar ways as them. Social validation strategies such as normalizing the process of seeking help for a mental health concern has shown success when the recommended treatment is from primary care physicians (Wilson et al., 2008). It may be worth investigating whether messages that enhance social validation through normalizing the use of mental health treatment, could increase compliance with mental health treatment recommendations.

\section{Limitations}

Although the present study had strengths, there were also important limitations. The first limitation of this study was the use of convenience sampling. The current study utilized SONA, an online research pool, which limited participation in the study to individuals enrolled in psychology courses at Illinois State University. The use of convenience sampling likely recruited a sample that was not at a particular need for interventions geared at improving perceptions of mental health treatment and increasing treatment utilization. The sample was comprised of a disproportionate number of young adults and females, which likely contributed to the ceiling effects on attitudes towards and intentions to engage in psychological help. Specifically, 83.2\% of the sample identified as female and research suggests that females typically endorse more favorable attitudes towards counseling when compared to males (Gonzalez, Alegria, \& Prihada, 2005). In addition, the sample also included mostly young adults as the mean age was 19.8. This is significant because young adults' perception of mental health services appears to be improving at the greatest rate. A cross sectional study analyzing data sets from 2 National Comorbidity Surveys conducted from 1990-1992 and 2001-2003 suggests that individuals between the ages of 
15-24 have shown the most favorable change in attitudes towards seeking psychological help (Mojtabai, 2007).

Additionally, researchers conjecture that stigma reduction initiatives on college campuses may be increasing student's willingness to engage in psychological help seeking (Eisenber, Hunt, $\&$ Speer, 2012). In fact, increased student engagement in the mental health stigma reducing organization, Active Minds, has shown to lead to increases in college students' willingness to refer peers to counseling services (Sontag-Padilla et. al., 2018). This finding provides initial evidence that providing awareness about mental health concerns and treatment could increase help seeking behaviors. It is also likely that the participants in this survey have been exposed to messages that normalize mental health treatment seeking. Specifically, ISU's Center for Teaching, Learning, and Technology recommends that professors include a message regarding the accessibility of ISU's Student Counseling Services on course Syllabi. These messages could be increasing attitudes towards and intentions to engage in psychological treatment through normalizing the occurrence of mental health concerns. Since the current study sample consists of mostly female students who have likely been exposed to a form of stigma reduction initiatives on their college campus, it is not surprising that attitudes and intentions to engage in psychological help seeking were favorable at baseline.

Another important limitation of this study is the use of hypothetical message sources. Participants were asked to "imagine" that they were speaking with either an undergraduate student or a medical doctor. Although the manipulation check analysis indicated that participants did view the doctor source as moderately more authoritative than the undergraduate source, the manipulation of message sources may be more impactful in real life. It is plausible that individuals may be less influenced by hypothetical authoritative sources since contextual clues 
such as an authoritative source's uniform, badge, or proof of degrees cannot be perceived visually. Past research suggests that authoritative uniforms impact compliance with recommendations (Bickman, 1974; Bushman, 1984; Bushman, 1988) and other researchers have discussed the effectiveness of establishing credibility through means such as dressing professionally, displaying books, and showcasing diplomas (Bergner, 2013). The source manipulation may have also been weakened because the messages used in the current study were crafted to fall below a fifth-grade reading level. In real life, medical doctors may use more technical language that could bolster the message source's credibility. Additionally, the messages used in the current study did not provide any statistical outcomes or information regarding research that supports the use of mental health treatment. Instead the messages used in the current study discussed general life outcomes which may have already been known to the participants. Because the messages lacked statistical evidence and would not require high levels of expertise to communicate, the perception of the doctor's level of authority may have been decreased. The lack of contextual clues and advanced language may have also weakened the credibility of the hypothetical doctor source in this study.

Similar to the shortcomings of the hypothetical source manipulation, another limitation of this study is that actual help seeking behavior was not measured. Instead of measuring actual help seeking behavior, participants were asked to rate their attitudes towards and intentions to seek psychological help in a hypothetical manner. Additionally, decisions to seek information about psychological treatment were assessed as opposed to rates of seeking psychological treatment. Although the current study utilized hypothetical scenarios because they have been deemed advantageous for highly personal topics that may be socially sensitive (Schoenberg \& Ravda, 2002), reactions to vignettes cannot fully predict future behaviors. Furthermore, assessing 
proximal measures to psychological help seeking instead of actual help seeking may be minimizing the complexity and interplay of factors that influence obtainment of psychological help. For example, attitudes towards and intentions to seek mental health treatment are not the only factors that influence whether an individual attends mental health treatment. Research has shown that other notable factors such as an individual's level of mental health literacy (Bonabi et al., 2016) and a person's perceived need for mental health treatment (Bonabi et al., 2016; Mojtabai et al., 2011) influence help seeking behaviors. Although an individual may have positive attitudes towards mental health treatment, these attitudes may not result in psychological help seeking because he or she may not perceive that he or she needs treatment. Likewise, a person with low mental health literacy may not recognize that his or her problems are symptoms of a mental health concern and therefore may never seek the appropriate treatment. However, even when a person is aware of his or her mental health conditions and reports a need for mental health treatment; other structural barriers may prevent someone from seeking services. For example, researchers have shown that structural barriers such as financial constraints, being unsure about where to seek treatment, and transportation conflicts also prevent individuals from seeking psychological help (Mojtabai et al., 2011; Sareen, 2007). Ultimately, collecting data on the outcome of actual psychological help seeking behavior would provide a superior level of information about the effectiveness of interventions targeted at increasing compliance with mental health treatment recommendations.

Finally, the surveys used in this study were conducted using an online platform. The use of an online survey design likely increased error variance and resulted in a significant amount of unusable data. An increase in error variance likely occurred because researchers have demonstrated that undergraduates often do not read all aspects of online survey instructions 
(Ramsey et al., 2016). Furthermore, the researcher was unable to monitor if participants were rushing through the survey, which resulted in the removal of 8 data sets because participants completed the survey in under two minutes. Data from 6 other participants was removed due to participants spending greater than one hour on the survey. Finally, 125 data sets were removed because participants took the pretest and posttest surveys without 24 hours between each survey. Taking the pretest and posttest within a 24-hour period could have encouraged participants to maintain consistency between their pretest and posttest responses. Ultimately, the use of an online survey resulted in a significantly decreased samples size because the rate at which participants completed the surveys and time between the surveys could not be fully controlled.

\section{Future Directions}

Future research in the area of increasing compliance with mental health treatment utilization could strive to sample populations that demonstrate diversity on identities such as gender, age, and educational status. Since the current study demonstrated that college students may already possess favorable attitudes towards and intentions to seek psychological help, it would likely be more worthwhile for researchers to evaluate compliance gaining strategies in samples who do not hold as favorable opinions towards psychological treatment. Targeting individuals who may hold less positive attitudes and intentions towards seeking psychological help, may help increase the utilization of mental health services.

Because another limitation of this study was the hypothetical nature of the treatment recommendations, future research could also evaluate the effectiveness of authoritative sources and message framing using real-world approaches. There is some evidence that authoritative sources may be particularly useful in real world settings. Specifically, studies utilizing field designs suggest that approaches such as the "warm hand-off", a process in which a medical 
doctor introduces the mental health service provider directly to the patient, is an effective way to increase mental health service use within integrated healthcare settings (Berge et al., 2017). Employing real life designs such as that used by Berge et al. (2017) will likely provide the most practical information about how to improve mental health treatment recommendations.

The purpose of the current study was to investigate how to increase the effectiveness of mental health treatment referrals. The results of the current study suggest that message framing manipulations and online source manipulations may not be an effective way to enhance compliance. Therefore, it is important to continue to investigate whether other compliance gaining strategies can increase rates of compliance with mental health treatment recommendations. It may be worthwhile to investigate the other five principles of social influence: liking, reciprocation, consistency, scarcity, and social validation (Cialdini \& Goldstein, 2002). Since it may be difficult for patients to follow through with mental health treatment due to stigma, it may be necessary to utilize more than one principle when referring patients to mental health treatment. Fortunately, some researchers have discussed the application and success of these principles in medical settings (Redelmeier \& Cialdini, 2002). Redelmeier and Cialdini (2002) suggest that physicians may utilize the liking principle by using encouraging words with patients and attending to their emotional concerns. The reciprocation principle may be utilized by providing exceptional patient care such as accommodating new appointment requests and the consistency principle may be utilized by having patients generate their own reasons for why mental health treatment may be a good solution (Redelmeier and Cialdini, 2002). Redelmeier and Cialdini (2002) also suggest that physicians can utilize the scarcity principle by making patients feel they are receiving unique treatment by using phrases such as, “Of all the patients I've seen today, you're on my mind the most because...". Lastly, physicians 
may utilize the social validation principle to encourage mental health treatment by communicating that other patients have successfully utilized mental health treatment. The messages used in the current study were not designed to normalize the use of mental health services so it may be beneficial for physicians to communicate that mental health treatment is a commonly used treatment. Additionally, the messages used in the current study communicated general life outcomes that "may" be achieved through counseling. It may be more effective for physicians to communicate the efficacy of mental treatment by providing specific data about the success of mental health treatment. It is easy to conceptualize how these other social influence strategies could be utilized by physicians making referrals to mental health care. Although some initial evidence suggests that these strategies are effective in medical settings (Redelmeier \& Cialdini, 2002), less is known about their application to mental health treatment referrals. Investigating the effects of these strategies independently as well as their combined effects could lead to higher rates of compliance with mental health service recommendations.

\section{Conclusions}

Although the present study's hypotheses were not supported, an unexpected contribution of this study is additional evidence that college aged individuals hold favorable opinions of mental health treatment. This finding is hopeful because it may suggest that the underutilization of mental health treatment may be reduced in subsequent years. However, as discussed early, obtainment of psychological help is influenced by a variety of factors. Although opinions towards psychological help appear to be positively increasing, additional efforts should continue to be made to increase the accessibility of mental health care. The primary strength of this study is the novel idea of evaluating the influence of message framing and source authority on compliance with mental health treatment recommendations. Message framing and source 
manipulations are common in the literature. For example, investigating the influence of authoritative sources dates back to 1970's (Bickman, 1974) and message framing manipulations have been widely studied in the physical health literature (Gallagher \& Updegraff, 2011;

O'Keefe \& Jensen, 2006). Despite the commonality of these manipulations, no researchers have examined their combined influence on increasing mental health treatment utilization. Although the current study did not find a significant influence of these combined communication strategies, it may be beneficial to correct for the limitations and evaluate these strategies in real world contexts. If a combined effect of framing and source was ultimately found, physicians could easily adopt the recommended communication techniques with little training or financial resources. Finding scalable solutions to combat the problem of underutilization of mental health treatment may ultimately improve the quality of life for a vast number of individuals. 


\section{REFERENCES}

Ajzen, I. (1985). From intentions to actions: A theory of planned behavior. Action Control: From Cognition to Behavior.11-39. https://doi.org/10.1007/978-3-642-69746-3_2

Ajzen, I. (1991). The theory of planned behavior. Organizational behavior and human decision processes, 50(2), 179-211. https://doi.org/10.1016/0749-5978(91)90020-T

Arora, R., Stoner, C., \& Arora, A. (2006). Using framing and credibility to incorporate exercise and fitness in individuals' lifestyle. Journal of Consumer Marketing, 23(4), 199-207. https://doi.org/10.1108/07363760610674329

Banks, S. M., Salovey, P., Greener, S., Rothman, A. J., \& Al, E. (1995). The effects of message framing on mammography utilization. Health Psychology,14(2), 178-184. https://doi.org/10.1037/0278-6133.14.2.178

Berge, J. M., Trump, L., Trudeau, S., Utržan, D. S., Mandrich, M., Slattengren, A., \& Wootten, M. (2017). Integrated care clinic: Creating enhanced clinical pathways for integrated behavioral health care in a family medicine residency clinic serving a low-income, minority population. Families, Systems, \& Health,35(3), 283-294. https://doi.org/10.1037/fsh0000285

Bergner, R. (2013). Therapeutic policies in the conduct of psychotherapy. In K. Davis, R. Bergner, F. Lubuguin, \& W. Schwartz (Eds.), Advances in Descriptive Psychology (Vol. 10, pp. 175-196). Ann Arbor, MI: Descriptive Psychology Press.

Bickman, L. (1974). The social power of a uniform. Journal of Applied Social Psychology,4(1), 47-61. https://doi.org/10.1111/j.1559-1816.1974.tb02599.x 
Borowsky, S. J., Rubenstein, L. V., Meredith, L. S., Camp, P., Jackson-Triche, M., \& Wells, K. B. (2000). Who is at risk of nondetection of mental health problems in primary care? Journal of General Internal Medicine,15(6), 381-388. https://doi.org/10.1046/j.1525-1497.2000.12088.x

Block, L. G., \& Keller, P. A. (1995). When to accentuate the negative: The effects of perceived efficacy and message framing on intentions to perform a health-related Behavior. Journal of Marketing Research,32(2), 192. https://doi.org/10.1177/002224379503200206

Brown, R. L., \& Rounds, L. A. (1995). Conjoint screening questionnaires for alcohol and other drug abuse: criterion validity in a primary care practice. Wisconsin Medical Journal, 94(3), 135-140.

Bruijn, G. J., Out, K., \& Rhodes, R. E. (2014). Testing the effects of message framing, kernel state, and exercise guideline adherence on exercise intentions and resolve. British Journal of Health Psychology, 19(4), 871-885. https://doi.org/10.1111/bjhp.12086

Bushman, B. J. (1984). Perceived symbols of authority and their influence on compliance. Journal of Applied Social Psychology,14(6), 501-508. https://doi.org/10.1111/j.1559-1816.1984.tb02255.x

Bushman, B. J. (1988). The effects of apparel on compliance. Personality and Social Psychology Bulletin,14(3), 459-467. https://doi.org/10.1177/0146167288143004

Cameron, R. P., \& Gusman, D. (2003). The primary care PTSD screen (PC-PTSD): development and operating characteristics. Primary Care Psychiatry, 9(1), 9-14. https://doi.org/10.1185/135525703125002360 
Case, K. R., Lazard, A. J., Mackert, M. S., \& Perry, C. L. (2018). Source credibility and e cigarette attitudes: implications for tobacco communication. Health communication, 33(9), 1059-1067. https://doi.org/10.1080/10410236.2017.1331190

Cialdini, R. (2002). The science and practice of persuasion. The Cornell Hotel and Restaurant Administration Quarterly,43(2), 40-50. https://doi.org/10.1177/001088040204300204

Cialdini, R. B., \& Goldstein, N. J. (2004). Social influence: Compliance and conformity. Annual Review of Psychology,55(1), 591-621. https://doi.org/10.1146/annurev.psych.55.090902.142015

Cialdini, R. B., \& Trost, M. R. (1998). Social influence: Social norms, conformity, and compliance. In D. T. Gilbert, S. T. Fiske, \& G. Lindzey (Eds.), The Handbook of Social Psychology (4th ed., Vol. 2, pp. 151-192).

Cialdini, R. B., \& Rhoads, K. V. (2001). Human behavior and the marketplace. Marketing Research, 13(3), 8 .

Corrigan, P. W., \& Penn, D. L. (1999). Lessons from social psychology on discrediting psychiatric stigma. American Psychologist, 54(9), 765-776. https://doi.org/10.1037/0003066X.54.9.765

Corrigan, P. (2004). How stigma interferes with mental health care. American Psychologist, 59(7), 614-625.http://dx.doi.org/10.1037/0003-066X.59.7.614

Corrigan, P. W., Morris, S. B., Michaels, P. J., Rafacz, J. D., \& Rüsch, N. (2012). Challenging the public stigma of mental illness: a meta-analysis of outcome studies. Psychiatric services, 63(10), 963-973. https://doi.org/10.1176/appi.ps.201100529 
Clement, S., Schauman, O., Graham, T., Maggioni, F., Evans-Lacko, S., Bezborodovs, N., \& Thornicroft, G. (2014). What is the impact of mental health-related stigma on helpseeking? A systematic review of quantitative and qualitative studies. Psychological Medicine,45(1), 11-27. https://doi.org/10.1017/S0033291714000129

Eastin, M. S. (2001). Credibility assessments of online health information: The effects of source expertise and knowledge of content. Journal of Computer-Mediated Communication, 6(4), JCMC643. https://doi.org/10.1111/j.1083-6101.2001.tb00126.x

Eisenberg, D., Hunt, J., \& Speer, N. (2012). Help seeking for mental health on college campuses: Review of evidence and next steps for research and practice. Harvard review of psychiatry, 20(4), 222-232. https://doi.org/10.3109/10673229.2012.712839

Esters, I. G., Cooker, P. G., \& Ittenbach, R. F. (1998). Effects of a unit of instruction in mental health on rural adolescents' conceptions of mental illness and attitudes about seeking help. Adolescence, 33(130), 469.

Falomir-Pichastor, J. M., Butera, F., \& Mugny, G. (2002). Persuasive constraint and expert versus non-expert influence in intention to quit smoking. European Journal Of Social Psychology, 32(2), 209-222. https://doi.org/10.1002/ejsp.67

French, J. R., Raven, B., \& Cartwright, D. (1959). The bases of social power. Classics of Organization Theory, 7, 311-320.

Gallagher, K. M., \& Updegraff, J. A. (2011). Health message-framing effects on attitudes, intentions, and behavior: a meta-analytic review. Annals of Behavioral Medicine, 43(1), 101-116. https://doi.org/10.1007/s12160-011-9308-7 
Gallagher, K. M., Updegraff, J. A., Rothman, A. J., \& Sims, L. (2011). Perceived susceptibility to breast cancer moderates the effect of gain-and loss-framed messages on use of screening mammography. Health Psychology, 30(2), 145. https://doi.org/10.1037/a0022264

Gonzalez, J. M., Alegria, M., \& Prihoda, T. J. (2005). How do attitudes toward mental health treatment vary by age, gender, and ethnicity/race in young adults?. Journal of Community Psychology, 33(5), 611-629. https://doi.org/10.1002/jcop.20071

Goodyear-Smith, F., \& Buetow, S. (2001). Power issues in the doctor-patient relationship. Health Care Analysis, 9(4), 449-462. https://doi.org/10.1023/A:1013812802937

Griffiths, K. M., Carron-Arthur, B., Parsons, A., \& Reid, R. (2014). Effectiveness of programs for reducing the stigma associated with mental disorders. A meta-analysis of randomized controlled trials. World Psychiatry, 13(2), 161-175. https://doi.org/10.1002/wps.20129

Hammer, J. H., Parent, M. C., \& Spiker, D. A. (2018). Mental help seeking attitudes scale (MHSAS): Development, reliability, validity, and comparison with the ATSPPH-SF and IASMHS-PO. Journal of Counseling Psychology, 65(1) 74. https://doi.org/10.1037/cou0000248

Hammer, J. H., \& Spiker, D. A. (2018). Dimensionality, reliability, and predictive evidence of validity for three help-seeking intention instruments: ISCI, GHSQ, and MHSIS. Journal of Counseling Psychology, 65(3), 394. https://doi.org/10.1037/cou0000256

Hu, Y., \& Shyam Sundar, S. (2010). Effects of online health sources on credibility and behavioral intentions. Communication Research, 37(1), 105-132. https://doi.org/10.1177/0093650209351512 
Jones, L. W., Sinclair, R. C., Rhodes, R. E., \& Courneya, K. S. (2004). Promoting exercise behaviour: An integration of persuasion theories and the theory of planned behaviour. British Journal of Health Psychology, 9(4), 505-521. https://doi.org/10.1348/1359107042304605

Jones, L. W., Sinclair, R. C., \& Courneya, K. S. (2003). The effects of source credibility and message-framing on exercise intentions, behaviors and attitudes: An integration of the elaboration likelihood model and prospect theory. Journal Of Applied Social Psychology, 33(1), 179-196. https://doi.org/10.1111/j.1559-1816.2003.tb02078.x

Karakostas, A., \& Zizzo, D. J. (2016). Compliance and the power of authority. Journal Of Economic Behavior And Organization, 124, 67-80. https://doi.org/10.1016/j.jebo.2015.09.016

Kareklas, I., Muehling, D. D., \& Weber, T. J. (2015). Reexamining health messages in the digital age: A fresh look at source credibility effects. Journal of Advertising, 44(2), 88-104. https://doi.org/10.1080/00913367.2015.1018461

Kessler, R. C., Andrews, G., Colpe, L. J., Hiripi, E., Mroczek, D. K., Normand, S. L., .\& Zaslavsky, A. M. (2002). Short screening scales to monitor population prevalences and trends in non-specific psychological distress. Psychological Medicine, 32(6), 959-976. https://doi.org/10.1017/S0033291702006074

Kessler, R. C., Barker, P. R., Colpe, L. J., Epstein, J. F., Gfroerer, J. C., Hiripi, E., \& Zaslavsky, A. M. (2003). Screening for serious mental illness in the general population. Archives of General Psychiatry, 60(2), 184-189. https://doi.org/10.1001/archpsyc.60.2.184 
Kessler, R. C., Chiu, W. T., Demler, O., \& Walters, E. E. (2005). Prevalence, severity, and comorbidity of 12-month DSM-IV disorders in the National Comorbidity Survey Replication. Archives of General Psychiatry, 62(6), 617-627. https://doi.org/10.1001/archpsyc.62.6.617

Kroenke, K., Spitzer, R. L., \& Williams, J. B. (2001). The PHQ-9: validity of a brief depression severity measure. Journal of General Internal Medicine, 16(9), 606-613. https://doi.org/10.1046/j.1525-1497.2001.016009606.x

Kroenke, K., Spitzer, R. L., Williams, J. B., Monahan, P. O., \& Löwe, B. (2007). Anxiety disorders in primary care: prevalence, impairment, comorbidity, and detection. Annals of Internal Medicine, 146(5), 317-325. https://doi.org/10.7326/0003-4819-146-5200703060-00004

Lannin, D. G., Vogel, D. L., Brenner, R. E., Abraham, W. T., \& Heath, P. J. (2016). Does selfstigma reduce the probability of seeking mental health information?. Journal of Counseling Psychology, 63(3), 351. https://doi.org/10.1037/cou0000108

Li, W., Dorstyn, D. S., \& Denson, L. A. (2014). Psychosocial correlates of college students' help-seeking intention: A meta-analysis. Professional Psychology: Research and Practice, 45(3), 163. https://doi.org/10.1037/a0037118

Lipscomb, T. J., Root, T., \& Shelley, K. (2004). Strategies for seeking mental health services. Services Marketing Quarterly, 25(4), 1-12. https://doi.org/10.1300/J396v25n04_01

Mavandadi, S., Wright, E., Klaus, J., \& Oslin, D. (2017). Message framing and engagement in specialty mental health care. Psychiatric Services, 69(3), 308-314. https://doi.org/10.1176/appi.ps.201700251 
Meulenaer, S. D., Pelsmacker, P. D., \& Dens, N. (2017). Power distance, uncertainty avoidance, and the effects of source credibility on health risk message compliance. Health Communication,33(3), 291-298. https://doi.org/10.1080/10410236.2016.1266573

Milgram, S. (1974). Obedience to authority: An experimental view. New York: Harper \& Row. Mojtabai, R., Olfson, M., Sampson, N. A., Jin, R., Druss, B., Wang, P. S., ... \& Kessler, R. C. (2011). Barriers to mental health treatment: results from the National Comorbidity Survey Replication. Psychological Medicine, 41(8), 1751-1761. https://doi.org/10.1017/S0033291710002291

Nadler, A. (1990). Help-seeking behavior as a coping resource. In M. Rosenbaum (Ed.), Learned Resourcefulness: On coping skills, self-control, and adaptive behavior (pp. 127-162). New York: Springer.

Olynick, J., Iliopulos, A., \& Li, H. Z. (2017). Physician verbal compliance-gaining strategies and patient satisfaction. Health Education,117(6), 551. https://doi.org/10.1108/HE-01-20170011

O’keefe, D. J., \& Jensen, J. D. (2006). The advantages of compliance or the disadvantages of noncompliance? A meta-analytic review of the relative persuasive effectiveness of gainframed and loss-framed messages. Annals of the International Communication Association, 30(1), 1-43. https://doi.org/10.1080/23808985.2006.11679054

O'Keefe, D. J., \& Jensen, J. D. (2009). The relative persuasiveness of gain-framed and lossframed messages for encouraging disease detection behaviors: A meta-analytic review. Journal of Communication, 59(2), 296-316. https://doi.org/10.1111/j.14602466.2009.01417.x 
O'Keefe, D. J., \& Jensen, J. D. (2007). The relative persuasiveness of gain-framed loss-framed messages for encouraging disease prevention behaviors: A meta-analytic review. Journal of health communication, 12(7), 623-644. https://doi.org/10.1080/10810730701615198

Prochaska, J. J., Sung, H. Y., Max, W., Shi, Y., \& Ong, M. (2012). Validity study of the K6+ scale as a measure of moderate mental distress based on mental health treatment need and utilization. International Journal of Methods in Psychiatric Research, 21(2), 88-97. https://doi.org/10.1002/mpr.1349

Ramsey, S. R., Thompson, K. L., McKenzie, M., \& Rosenbaum, A. (2016). Psychological research in the internet age: The quality of web-based data. Computers in Human Behavior, 58, 354-360. https://doi-org.libproxy.lib.ilstu.edu/10.1016/j.chb.2015.12.049

Raven, B. H. (2008). The bases of power and the power/interaction model of interpersonal influence. Analyses of Social Issues and Public Policy, 8(1), 1-22. https://doi.org/10.1111/j.1530-2415.2008.00159.x

Redelmeier, D. A., \& Cialdini, R. B. (2002). Problems for clinical judgement: 5. Principles of influence in medical practice. CMAJ : Canadian Medical Association Journal 166(13), $1680-1684$.

Regier, D. A., Goldberg, I. D., \& Taube, C. A. (1978). The de facto US mental health services system: a public health perspective. Archives of General Psychiatry, 35(6), 685-693. https://doi.org/10.1001/archpsyc.1978.01770300027002

Rothman, A. J. (2000). Toward a theory-based analysis of behavioral maintenance. Health Psychology, 19(1S), 64. https://doi.org/10.1037/0278-6133.19.Suppl1.64

Saporito, J. M., Ryan, C., \& Teachman, B. A. (2011). Reducing stigma toward seeking mental health treatment among adolescents. Stigma Research and Action, 1(2), 9. 
Simon, G. E., VonKorff, M., \& Barlow, W. (1995). Health care costs of primary care patients with recognized depression. Archives of General Psychiatry, 52(10), 850-856. https://doi.org/10.1001/archpsyc.1995.03950220060012

Schurman, R. A., Kramer, P. D., \& Mitchell, J. B. (1985). The hidden mental health network: treatment of mental illness by nonpsychiatrist physicians. Archives of General Psychiatry, 42(1), 89-94. https://doi.org/10.1001/archpsyc.1985.01790240091010

Spitzer, R. L., Kroenke, K., Linzer, M., Hahn, S. R., Williams, J. B., Verloin deGruy, F., \& Davies, M. (1995). Health-related quality of life in primary care patients with mental disorders: results from the PRIME-MD 1000 Study. Jama, 274(19), 1511-1517. https://doi.org/10.1001/jama.1995.03530190025030

Thornicroft, G., Mehta, N., Clement, S., Evans-Lacko, S., Doherty, M., Rose, D., \& Henderson, C. (2016). Evidence for effective interventions to reduce mental-health-related stigma and discrimination. The Lancet, 387(10023), 1123-1132. https://doi.org/10.1016/S01406736(15)00298-6

Wang, P. S., Demler, O., \& Kessler, R. C. (2002). Adequacy of treatment for serious mental illness in the United States. American Journal of Public Health, 92(1), 92-98. https://doi.org/10.2105/AJPH.92.1.92

Vogel, D. L., Wade, N. G., \& Haake, S. (2006). Measuring the self-stigma associated with seeking psychological help. Journal of Counseling Psychology, 53(3), 325337.http://dx.doi.org/10.1037/0022-0167.53.3.325

Wang, P. S., Lane, M., Olfson, M., Pincus, H. A., Wells, K. B., \& Kessler, R. C. (2005). Twelvemonth use of mental health services in the United States: results from the National Comorbidity Survey Replication. Archives of General Psychiatry, 62(6), 629-640. 
Webb, T. L., \& Sheeran, P. (2006). Does changing behavioral intentions engender behavior change? A meta-analysis of the experimental evidence. Psychological Bulletin, 132(2), 249. https://doi.org/10.1037/0033-2909.132.2.249

Wilson, C., Deane, F., Marshall, K., \& Dalley, A. (2008). Reducing adolescents' perceived barriers to treatment and increasing help-seeking intentions: Effects of classroom presentations by general practitioners. Journal of Youth \& Adolescence, 37(10), 1257 1269. https://doi.org/10.1007/s10964-007-9225-z

Wilson, D. K., Purdon, S. E., \& Wallston, K. A. (1988). Compliance to health recommendations: A theoretical overview of message-framing. Health Education Research, 3(2), 161-171. https://doi.org/10.1093/her/3.2.161

Wrench, J. S., \& Booth-Butterfield, M. (2003). Increasing patient satisfaction and compliance: An examination of physician humor orientation, compliance-gaining strategies, and perceived credibility. Communication Quarterly, 51(4), 482-503. https://doi.org/10.1080/01463370309370169

Zolnierek, K. B. H., \& DiMatteo, M. R. (2009). Physician communication and patient adherence to treatment: a meta-analysis. Medical Care, 47(8), 826. https://doi.org/10.1097/MLR.0b013e31819a5acc 


\title{
APPENDIX A: INFORMED CONSENT
}

\author{
Informed Consent Form \\ Department of Psychology, Illinois State University \\ Principal Investigators: Morgan Ess, B.A. Daniel G. Lannin, Ph.D.
}

For this research study, you must be at least 18 years of age to participate. You are ineligible to participate if you are currently within the European Economic Area. Please read this document carefully.

Description of the Study: This is an online research survey. You will be asked to answer questions about your mental health concerns as well as your beliefs about mental health and counseling. This study is divided into two parts. First, you will take part 1 of the survey and then you will be contacted within one week to complete part 2. You will be asked to provide your ISU email so that the researchers can send you part 2 of the survey. Your participation in this research is voluntary and will take approximately 20-30 minutes for each survey. You will spend approximately 40-60 minutes completing both parts of the study.

Purpose of the Study: The purpose of this study is to gather information about people's beliefs about mental health concerns and treatment options. We are interested in the overall responses of all of the people who participate in this study, not the responses of any one participant.

Possible Risks: You will be asked to provide personal information about yourself. Only your ULID will be used to identify data; data will only be accessed by the research team; however, as with any research study in which data are collected, there is potential risk of breach of confidentiality. If a breach of confidentiality occurs, information about your mental health could be exposed. This exposure may be a risk to your social reputation since mentally distressed individuals often experience social stigma. Some of the survey items may make you uncomfortable or distressed, but you are free to skip any item you choose, with no penalty to you. Specifically, you will be asked to provide information about your psychological distress. Psychological distress encompasses whether or not you have felt: nervous, hopeless, restless, worthless, depressed, and whether "everything was effortful" in the last 30 days. You will be told information about your level of psychological distress and how it compares to the rest of the population.

Possible Benefits: Participants may benefit by learning about this research, which can help them in their psychology course. They will also learn more about themselves and their beliefs about mental health concerns and treatment options; this might be a valuable learning experience.

Compensation: You will receive 1 SONA credit for completing both parts of the 2-part study. You will receive 0.5 points SONA credits for completing part 1 and 0.5 points for completing part 2 . Alternative means of credit may be available; please consult your instructor or class syllabus.

Confidentiality: Your name will not appear anywhere on the data or be linked to the data. The code number the Survey software utilizes will not be used to attempt to identify you by name. All data will be kept secure, in accord with the standards of the University, Federal regulations, and the American Psychological Association. While your instructor may know who does or does not agree to participate in the research before grades are posted, you will not be penalized if you choose to not participate. Any report of the data collected will be in summary form, without identifying individuals.

Opportunities to Question: If you have questions about this research project, you may contact Morgan Ess at mess@ilstu.edu. If you have questions about your rights as a participant, you may contact the Research Ethics \& Compliance Office rec@ilstu.edu at (309) 438-5527. 
Opportunities to Withdraw at Will: You may skip any questionnaire items or any part of this research you do not wish to do. If you decide now or at any point to withdraw this consent or stop participating, you are free to do so at no penalty to yourself.

Opportunities to be Informed of Results: In all likelihood, the results will be fully available at some time during the Fall 2019 semester. If you wish to be told the results of this research, please contact Morgan Ess, mess@ilstu.edu.

Additionally, if you feel distress at any point, please feel free to contact Student Counseling Services: call (309) 438-3655 or stop by room 320 of the Student Services Building to make an appointment.

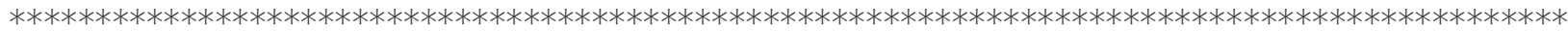

$* * * * * * * * * * * * * * *$

Feel free to print a copy of this page for your records

Clicking next indicates consent to participate, and you will need to provide your email address to receive SONA credit, so we know you participated. 


\section{APPENDIX B: DEBRIEFING STATEMENT}

\section{Debriefing}

\section{Purpose of the Study:}

The purpose of this study is to investigate ways to increase compliance with recommendations to obtain mental health counseling services. Researchers are investigating whether individuals will be more likely to attend counseling services if they are recommended by highly credible sources such as a medical doctor. Also, researchers are wondering if changing the format of the recommendations influences whether individuals want to attend counseling.

If you have any additional questions about the purpose of the study, please contact Morgan Ess at mess@ilstu.edu

If you are experiencing a psychological crisis after taking this survey, please call 911 for immediate help.

If you are feeling distressed after taking this survey and wish to speak to a mental health professional, you can contact Student Counseling Services: call (309) 438-3655 or stop by room 320 of the Student Services Building to make an appointment. If you are calling Student Counseling Services after hours please press "2" at the prompt to speak to a counselor. 